\title{
Hydroforming of elliptical cavities
}

\author{
W. Singer ${ }^{*}$ and X. Singer \\ Deutsches Elektronen-Synchrotron DESY, Notkestrasse 85, DE-22603 Hamburg, Germany \\ I. Jelezov \\ Institute for Nuclear Research RAS, 117312 Moscow, Russia \\ P. Kneisel \\ Jefferson Lab, Newport News, Virginia 23606, USA
}

(Received 24 September 2014; published 27 February 2015)

\begin{abstract}
Activities of the past several years in developing the technique of forming seamless (weldless) cavity cells by hydroforming are summarized. An overview of the technique developed at DESY for the fabrication of single cells and multicells of the TESLA cavity shape is given and the major rf results are presented. The forming is performed by expanding a seamless tube with internal water pressure while simultaneously swaging it axially. Prior to the expansion the tube is necked at the iris area and at the ends. Tube radii and axial displacements are computer controlled during the forming process in accordance with results of finite element method simulations for necking and expansion using the experimentally obtained strain-stress relationship of tube material. In cooperation with industry different methods of niobium seamless tube production have been explored. The most appropriate and successful method is a combination of spinning or deep drawing with flow forming. Several single-cell niobium cavities of the 1.3 GHz TESLA shape were produced by hydroforming. They reached accelerating gradients $E_{\text {acc }}$ up to $35 \mathrm{MV} / \mathrm{m}$ after buffered chemical polishing (BCP) and up to $42 \mathrm{MV} / \mathrm{m}$ after electropolishing (EP). More recent work concentrated on fabrication and testing of multicell and nine-cell cavities. Several seamless two- and three-cell units were explored. Accelerating gradients $E_{\text {acc }}$ of 30-35 MV/m were measured after $\mathrm{BCP}$ and $E_{\text {acc }}$ up to $40 \mathrm{MV} / \mathrm{m}$ were reached after EP. Nine-cell niobium cavities combining three three-cell units were completed at the company E. Zanon. These cavities reached accelerating gradients of $E_{\text {acc }}=30-35 \mathrm{MV} / \mathrm{m}$. One cavity is successfully integrated in an XFEL cryomodule and is used in the operation of the FLASH linear accelerator at DESY. Additionally the fabrication of bimetallic singlecell and multicell $\mathrm{NbCu}$ cavities by hydroforming was successfully developed. Several $\mathrm{NbCu}$ clad singlecell and double-cell cavities of the TESLA shape have been fabricated. The clad seamless tubes were produced using hot bonding or explosive bonding and subsequent flow forming. The thicknesses of $\mathrm{Nb}$ and $\mathrm{Cu}$ layers in the tube wall are about 1 and $3 \mathrm{~mm}$ respectively. The rf performance of the best $\mathrm{NbCu}$ clad cavities is similar to that of bulk $\mathrm{Nb}$ cavities. The highest accelerating gradient achieved was $40 \mathrm{MV} / \mathrm{m}$. The advantages and disadvantages of hydroformed cavities are discussed in this paper.
\end{abstract}

DOI: 10.1103/PhysRevSTAB.18.022001

PACS numbers: 29.20.Ej

\section{INTRODUCTION}

The hydroforming technique was worldwide developed in the past 30 years (see for example [1-3]). It is an established procedure now with millions of pieces produced - mainly of light parts for automotive application or various applications in the aerospace industry.

Though is seems reasonable and elegant to apply hydroforming for fabrication of elliptical cavities, the established fabrication procedure of elliptical SRF cavities consists of

\footnotetext{
waldemar.singer@desy.de

Published by the American Physical Society under the terms of the Creative Commons Attribution 3.0 License. Further distribution of this work must maintain attribution to the author $(s)$ and the published article's title, journal citation, and DOI.
}

deep drawing and electron beam welding (EBW) of the half cells in the iris and equator areas. This procedure is industrialized and has about 30 years of fabrication experience. In the past few years improvement of material quality control, the preparation for EBW and the welding parameters allowed to reach accelerating gradients close to $40 \mathrm{MV} / \mathrm{m}$ by applying advanced cavity treatment techniques such as electropolishing (EP) in combination with baking $[4,5]$.

The disadvantage of this method is that welding at the equator and iris of cells is very critical for rf performance, because they will be exposed to high magnetic or electric fields.

Therefore, thoroughly cleaning by ultrasonic degreasing, chemical etching, ultrapure water rinsing and clean room drying for welding is mandatory to avoid substandard 
welds. Also, clean conditions must be assured during welding and contaminating the weld area by touching after the last cleaning must be avoided. Since niobium is a strong getter material for oxygen, it is important to carry out the EB welds in a vacuum of $<10^{-5}$ mbar.

Therefore, a fabrication method which will avoid the welding in critical areas is very welcome. Two aspects have to be stressed here. First, the seamless cavity does not have the risk of equator weld purity degradation and therefore could improve the reliability towards achieving high gradients (the highest field in a cavity, which needs to be sustained by the superconducting material, exists near the equator). Furthermore, the heat affected zone (HAZ) and associated to it defects $[6,7]$ will be absent. It can be expected that the statistic in performance of seamless cavities for the series production will be better.

Second, a lower cost of fabrication can be assumed, especially for big series production.

Development of superconducting joints [8] can support the seamless option, too. This development would open the possibility to produce the cavities consisting of a rotationally symmetric cells part (by applying "seamless" fabrication technologies) and asymmetric end groups flanged to the cells.

The industrial fabrication of elliptical rf resonators or industrial devices with this technique is not yet developed. Such fabrication is a challenging task because of rather small wall thickness of the tubes and rather big ratio of the equator diameter to the iris. For example for the cavities of the TESLA shape this ratio is close to $3(212 \mathrm{~mm} / 70 \mathrm{~mm})$ and the wall thickness is about $3 \mathrm{~mm}$.

In addition some special properties of high purity niobium can cause problems for forming. On one hand it is very difficult to reach the uniform grains and homogenous distribution of strain-stress parameters; on the other hand niobium possesses low work hardening during deformation and tends to rupture.

Some efforts to fabricate seamless elliptical cavities were carried out in the past by applying techniques such as explosive forming [9], spinning [10] and hydroforming. Explosive forming requires about $60 \%$ elongation before break. It was successfully applied to $\mathrm{Cu}$ tubes, but failed for bulk niobium. Spinning was started in the 1990s at INFN Legnaro and it was demonstrated that single-cell spun cavity reached $E_{\text {acc }}$ similar to welded cavities (up to $40 \mathrm{MV} / \mathrm{m}$ ).

Most of the development was dedicated to hydroforming of elliptical cavities ranging in frequency from $300 \mathrm{MHz}$ to $3.9 \mathrm{GHz}$ in many Labs: CERN [11] and Cornell [12] in the 1980s, CEA SACLAY in 1990s [13,14] and some recent efforts at KEK [15] and Michigan State University [16]. These labs successfully produced cavities from copper. A $1.3 \mathrm{GHz}$ single-cell cavity hydroformed at CEA SACLAY from $\mathrm{Nb}$ of $\mathrm{RRR}=20$ reached a gradient of $E_{\mathrm{acc}}=18 \mathrm{MV} / \mathrm{m}$ after postpurification $[13,14]$.
A single-cell cavity hydroformed at KEK reached recently $30 \mathrm{MV} / \mathrm{m}$ [15].

DESY started the hydroforming development in collaboration with INR (Russia) in the 1990s and established a most consistent program. This "proof of principle" program has demonstrated that multicell cavities with high performance can be built by hydroforming and can be successfully used for operation in the accelerators.

The main results have been published up to now in conference proceedings; some have not been published at all. The comprehensive description of all steps of development and presentation of the main results in a review paper makes sense from our point of view, because of the high interest in this cavity manufacturing procedure-even though the interest is oscillating over time-in the context of mass production of cavities for projects such as the International Linear Collider (ILC).

\section{ARE THE MECHANICAL PROPERTIES OF NIOBIUM SUITABLE FOR HYDROFORMING?}

It is well known that the plasticity of most refractory metals increases with the temperature. Therefore the first decision for hydroforming concerns the working temperature during the hydroforming process. The main question was: How do the mechanical properties of $\mathrm{Nb}$ change with temperature and do we have to carry out hydroforming at room temperature or at elevated temperatures?

The tensile tests done at DESY on high purity niobium (RRR 300) in the temperature range between room temperature and $300^{\circ} \mathrm{C}$ have shown a small minimum of the elongation at break close to $125^{\circ} \mathrm{C}$, but no rise of elongation at elevated temperatures compared to the room temperature (Fig. 1). Data from literature confirmed these results, indeed up to $1000^{\circ} \mathrm{C}$ the elongation remains the same as at the room temperatures [17]. These data allow drawing an important conclusion: the hydroforming of niobium cavities can be done at room temperature which

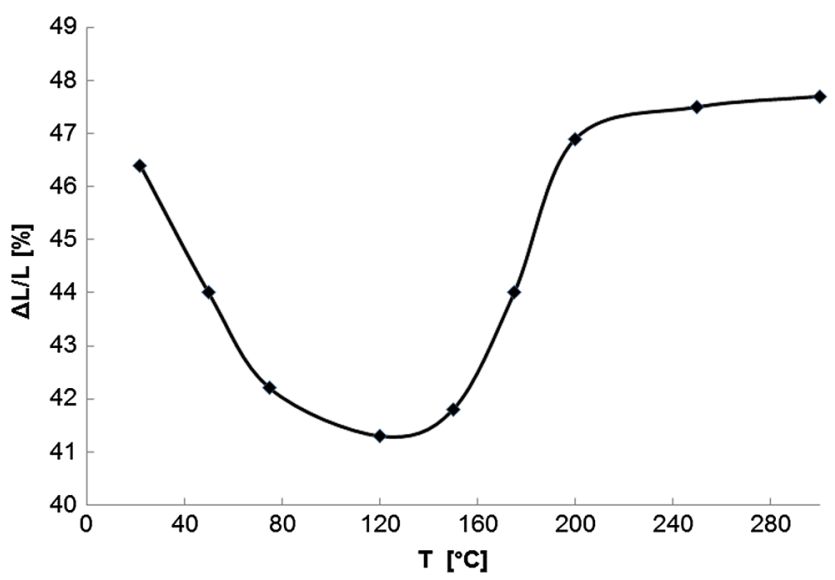

FIG. 1. Elongation at break vs temperature for high purity niobium. 
simplifies significantly the hydroforming technique and makes this procedure feasible.

Two additional aspects have been very beneficial and contributed to the success in the hydraulic forming of the $\mathrm{Nb}$ cavities.

The first one was the application of periodic stress change (pulsed stress). It was discovered in our experiments that the strain before onset of local thinning of the sample will be markedly increased (by almost $30 \%$ ) by its deforming during tensile test with pulsed stress (see Fig. 2). Probably the pull-release regime of the deformation artificially increases the normally low work hardening of $\mathrm{Nb}$ in low-yield strength regions and therefore shifts the fracture to higher elongations compared to monotonic increase of stress. The application of this pulse regime expressed as pressure variation in the tube during the hydroforming process has also proved to be advantageous.

The second aspect was the use of the correct strain rate $d \varepsilon / d T$ for niobium during the hydraulic expansion. Our experiments have shown in accordance with some literature data summarized in [18] that the deformation procedure should be rather slow. By keeping the strain rate below $10^{-3} \mathrm{~s}^{-1}$, a $10 \%$ higher strain before local thinning can be obtained.

It was important to find a reasonable way for seamless tube characterization concerning usability for hydroforming. The deformation in the case of hydroforming is more or less a biaxial expansion. Bulge testing is most appropriate for tube characterization, however it requires flattening of the tube piece, which introduces some work hardening and partly disturbs the properties. The scheme of bulge device (hydraulic expansion of the $\mathrm{Nb}$ disk into a round aperture) built at DESY can be seen in Fig. 3. The values of the stress $\sigma$ and the strain $\varepsilon$ at zenith can be determined by

$$
\sigma=\frac{p r}{2 t} \quad \text { and } \quad \varepsilon=\ln \frac{t}{t_{0}}
$$
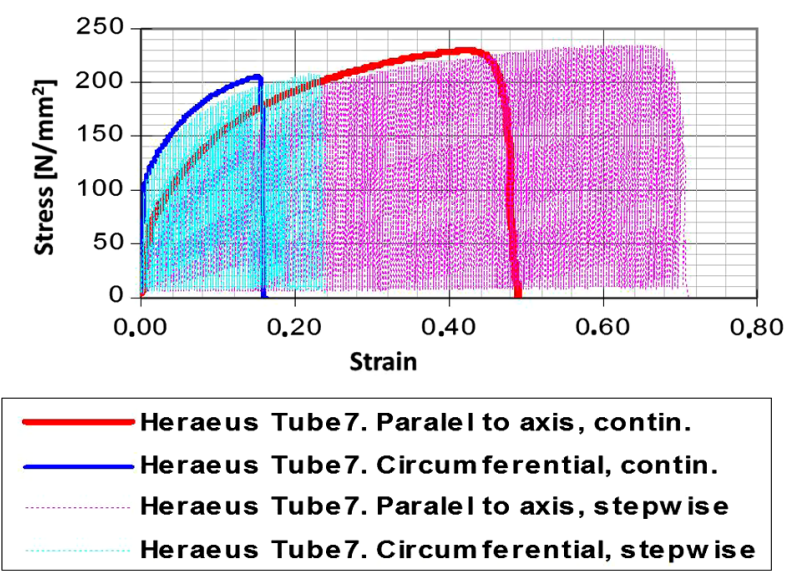

FIG. 2. Comparison of the tensile test result in continuos and pulsed (stepwise) stress regime.

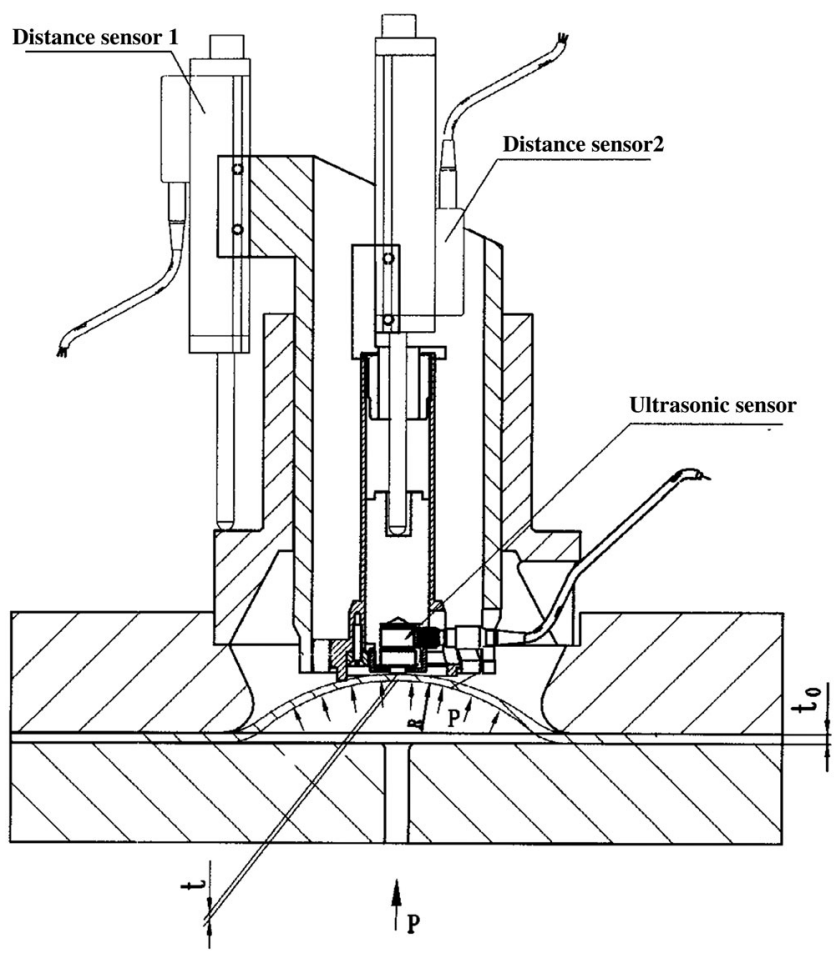

FIG. 3. Scheme of the bulge test device.

The pressure $p$, radius of the curvature $r$ and thickness $t$ in zenith of the sample are measured during the deformation procedure with a curvature sensor and an ultrasonic device. The bulge procedure can be done both by pulsed stress and continuously [19].

A series of bulge and tensile tests have shown an unfortunate anisotropy of the mechanical properties of the tubes; the elongation before local thinning of the wall was in all cases much higher in axial, as in the more critical and important circumferential directions needed for hydroforming (see for example Fig. 2). Therefore, it was decided that a tensile test of the cutout from the tube and from a flattened ring will give the required information about usability of the tube and will be sufficient. Additionally, the grain structure analysis was done on all types of tubes.

Based on our experiences with high purity $\mathrm{Nb}$ sheets [20] the main goal was to have fully recrystallized tubes with uniform grain structure and grain sizes of 50-100 $\mu \mathrm{m}$. In this case, the mechanical properties are close to optimal for hydroforming. The annealing parameters have to be approaching to $800^{\circ} \mathrm{C}, 2$ hours, but the final annealing temperature for each type of tube was adapted to its production procedure.

As is well known, the strain-hardening coefficient $\boldsymbol{n}$ is important for biaxial deformation; high $\boldsymbol{n}$ reduces the amount of local thinning. The $\boldsymbol{n}$ coefficient is close to maximum for high purity $\mathrm{Nb}$ around 0.3 for these conditions.

Initially, all forming experiments have been done with $\mathrm{Cu}$ tubes from stock, since $\mathrm{Cu}$ shows much higher work 
hardening and elongation before local thinning compared to $\mathrm{Nb}$ (the strain-hardening coefficient of $\mathrm{Cu} \boldsymbol{n}_{\mathrm{Cu}}=0.45$ ) and it is much easier to proceed with this material without burst. The final definition of the procedure and the determination of the parameters has been done with $\mathrm{Nb}$ tubes.

\section{FEM SIMULATIONS OF HYDROFORMING}

Generally, the forming procedure of elliptical cavities consists of two stages: reduction of the tube in the iris area (necking) and expansion of the tube in the equator area (hydroforming). The main parameters of the procedures are internal pressure, axial compression length (axial displacement) and shape change (radius change).

Experiences have shown that numerical simulation of the necking and hydraulic expansion of the tube is very useful especially at the beginning. The finite element method (FEM) simulation gives the starting point for the hydroforming parameters which can be additionally tuned by comparison between the theoretical and experimentally observed parameters. A lot of simulation were performed with the finite element code ANSYS, assuming the elastoplastic behavior in accordance with stress-strain curve and isotropic hardening rules [21,22].

The calculations were carried out for definite tubes foreseen for hydroforming using the true strain-stress characteristic related from the bulge test.

The main aim of the FEM simulations was to find a way of forming by minimization of the stress in critical areas, thus avoiding reaching the ultimate tensile strength. The simulations, as well as the hydroforming experiments, have been done first on $\mathrm{Cu}$ tubes.

As an example, the simulated stress distribution and wall thickness change after the necking process at the end of a tube is shown in Figs. 4(a) and 4(b) for some tubes and compared with experiment results. The left points on Fig. 4(a) correspond to the upper part of Fig. 4(b).

It can be seen that some reduction of the tube wall thickness occurred during necking.

For the simulation of the expansion process the tube form and stress distribution, reached after necking, has to be taken into account. The simulations of expansion give information on the relationship between the radial growth and applied internal pressure as a function of the axial displacement (path of the expansion). The results for stress distribution and radial growth are shown in Figs. 5(a) and 5(b) and compared to experimental data in 5(a). From the good agreement one can conclude that the simulation describes the reality rather well and can be used for the first iteration of the hydroforming procedure.

The dimensional inspection of the hydroformed double cells has shown that in some cases during the forming process the radius of the iris decreased by about $1-1.5 \mathrm{~mm}$. To understand this phenomenon further FEM simulations had to be done as well as a series of experiments on double

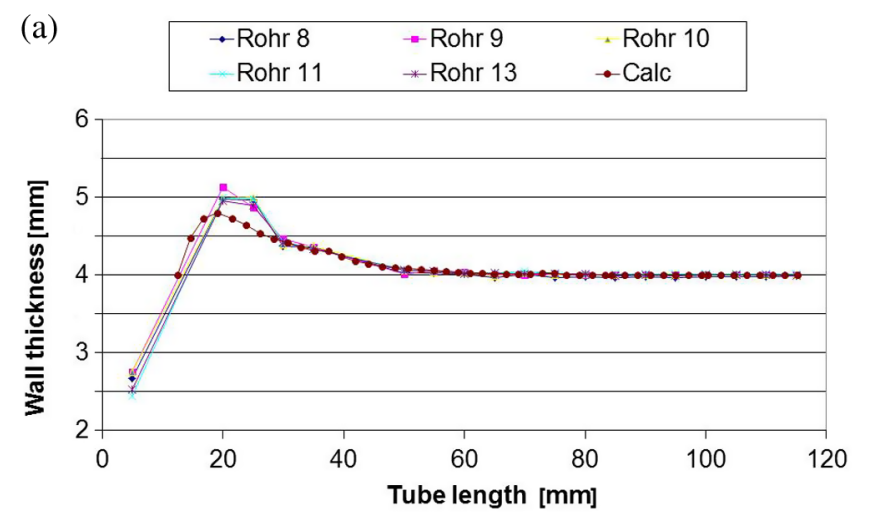

(b)

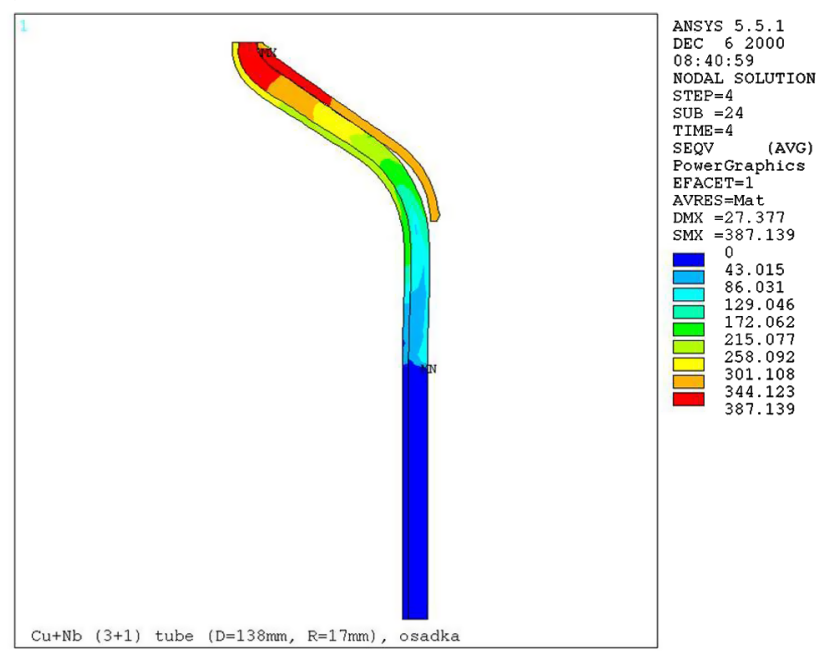

FIG. 4. (a) Comparison of FEM simulated wall thicknesses $T$ after necking with experimental data (Tubes 8-9,11,13). (b) Calculated stress distribution after necking.

cells from copper and niobium. It turned out that most of the iris reduction can be avoided by a sharp increase of the internal pressure at the initial stage of tube expansion (approximately 30-40 bar per $\mathrm{mm}$ of axial displacement).

The results of computer simulations related to iris behavior, depending on the pressure during the initial stage of hydroforming, is shown in Figs. $6 \mathrm{a}$ and $6 \mathrm{~b}$ for $\mathrm{Nb}$. The factor $K=1$ represents the minimal initial pressure required for successful hydroforming. In other experiments the pressure was increased to $K=1.75-2.5$. Increasing of the pressure up to $K=2$ can minimize the effect of the iris reduction, but further increase of pressure has no significant influence on it [Fig. 6(a)]. The experiments have been in good agreement with these findings. The final corrections of the iris shape have been accomplished by calibration at high pressure 500-1000 (see below).

\section{HYDROFORMING TECHNIGUE}

The combination of tube necking in the iris area and subsequent tube expansion in the equator area permitted to achieve a more or less homogeneous distribution of the 
(a)

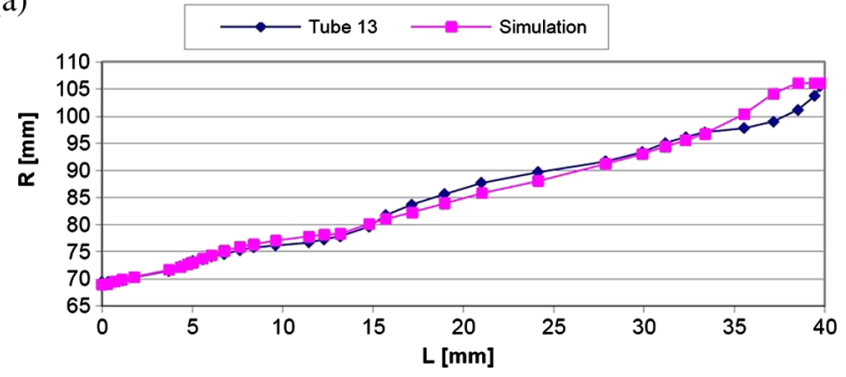

(b)

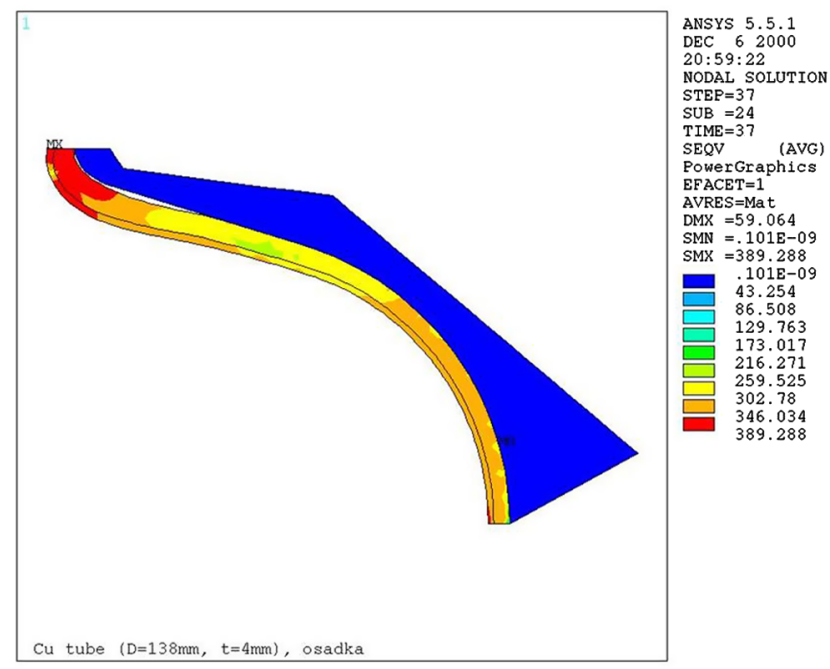

FIG. 5. (a) Simulation of radius growth during hydroforming in comparison with experiment (Tube 13). (b) Calculated stress distribution after hydroforming.

stress around the tube and therefore the forming without damage. This procedure eliminates the need for an intermediate annealing during hydroforming of single-cell as well as multicell cavities.

\section{A. Necking procedure}

The development of the reduction of the tube diameter at the iris area (necking) is an even more challenging task than its expansion (hydroforming itself) and demanded even more efforts.

Several necking methods (hydraulic necking, electromagnetic strike necking, round knead, spinning) were tested at DESY before the current necking procedure was established.

The best necking results (rather smooth surface, uniform wall, small wall thickness reduction, good reproducibility) were achieved by using a specially profiled ring moving in radial and axial directions. The radius of the profiled ring touching the tube is almost the same as the outside radius of the tube, which allows a small angle between the ring and the tube to be maintained. Explored methods of the tube necking at the iris and at the tube ends are shown in Figs. 7(a), 7(b), 8(a), and 8(b). Plates with holes and ball (a)
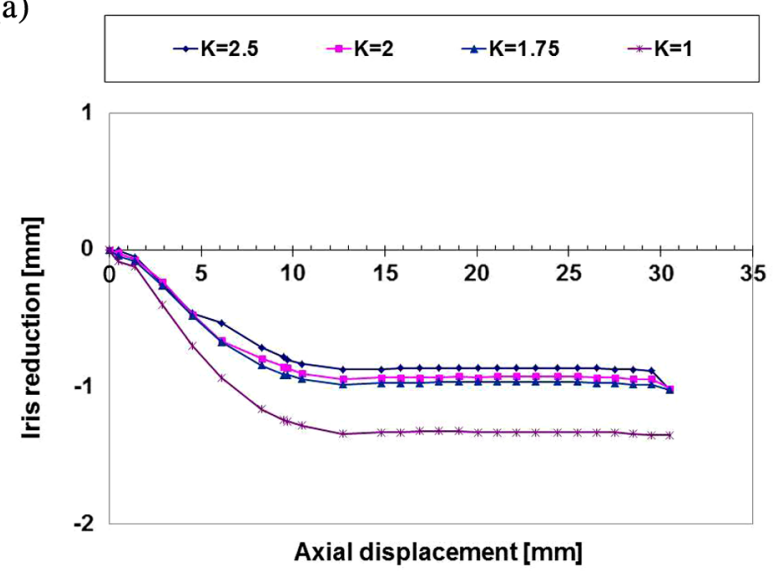

(b)

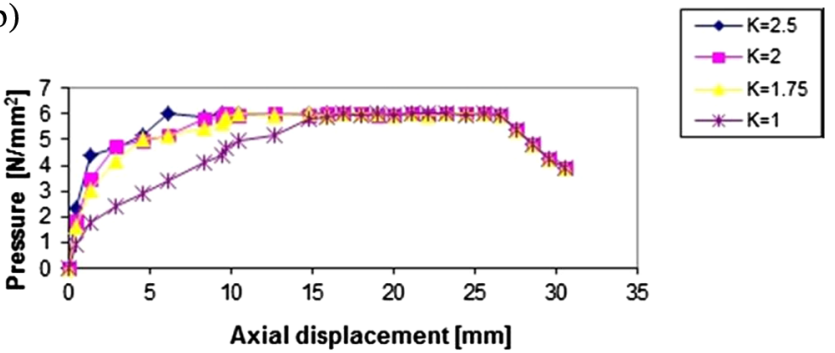

FIG. 6. (a) and (b) FEM simulations of the iris reduction vs axial displacement (upper image) and of internal pressure vs axial displacement (lower image).

bearings prevent the tube from bending, but at the same time allow tube rotation. The combinations of radial and axial movement of the profiled ring ensure a circumferentially uniform wall thickness at the iris area without its essential reduction.

The software managed the axial movement continuously from position one to position two; from position two to position three etc. following the declined trajectory [Figs. 8(a) and 8(b)]. Simultaneously the tube is compressed axially. The compression value depends on the contact angle between the necking ring and the tube. Developed ideas have been summarized in a patent [23].

A tube necking device for laboratory scale experiments utilizing the described principles was designed and constructed at DESY (Fig. 9).

The device for necking of $\mathrm{Nb}$ tubes has been designed for inside diameters of 130 or $150 \mathrm{~mm}$ and permits necking of single-cell, double-cell or three-cell cavities of ILC-like shape [TESLA, low loss (LL) or Reentrant (RE)]. The machine consists of several transversally oriented plates. Two hydraulic cylinders provide the axial and radial movement of the profile ring. The cylinders are equipped with position and pressure sensors. The computer control of the device allows one to reproducibly apply the necking parameters.

The combination of radial and axial movements results in uniformity of circumferential wall thickness at the iris area without remarkable reduction of the wall thickness 

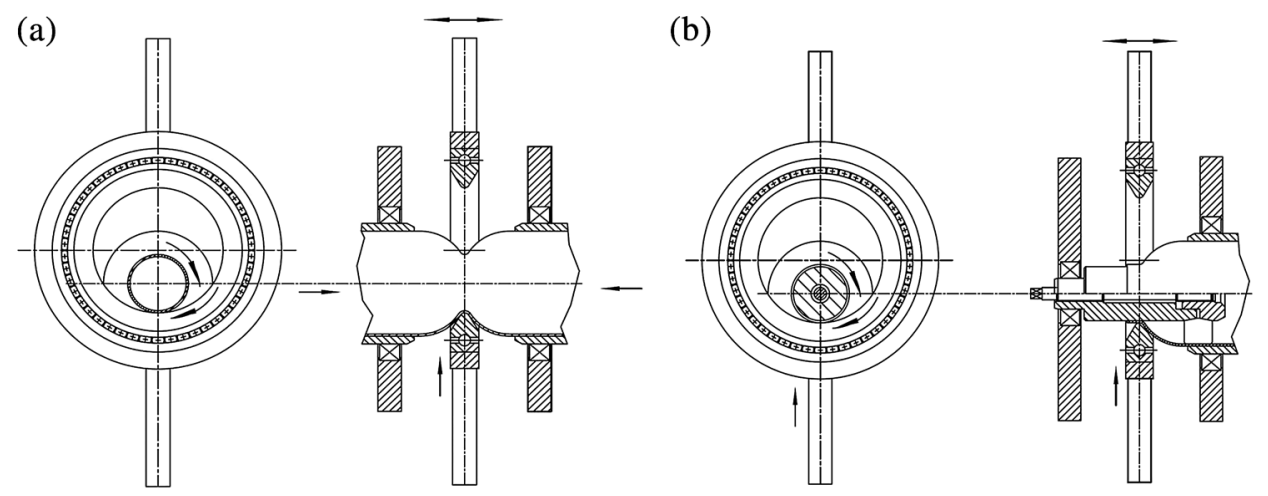

FIG. 7. (a) Principle of the necking at the iris. (b) Principle of the necking at the tube end.

(not more that 20\%). Our experience showed that the machine is functioning very well.

One example of the necked niobium tubes can be seen in Fig. 10.

\section{B. Expansion procedure}

A special machine for hydroforming experiments on a laboratory level was designed and built at INR institute in Russia $[2,24,25]$ within the scope of the collaboration with DESY. The designed machine allows variations of
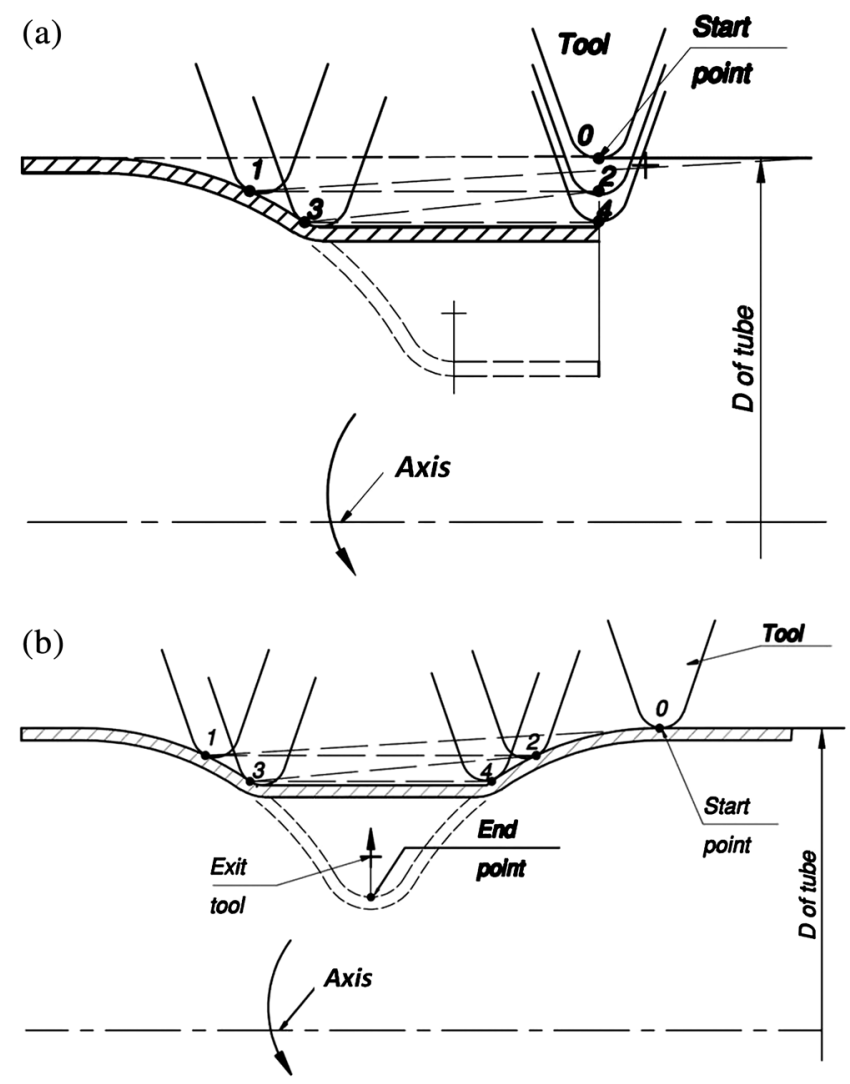

FIG. 8. (a) Principle of profile ring movement during the end cell necking. (b) Principle of the profile ring movement during iris necking. hydroforming parameters, different constraint options and is capable to produce elliptical cavities of different shapes (TESLA, RE, LL etc.) up to three-cell units.

The device is schematically shown in Fig. 11. The main part of the hydroforming machine can be seen in Fig. 12.

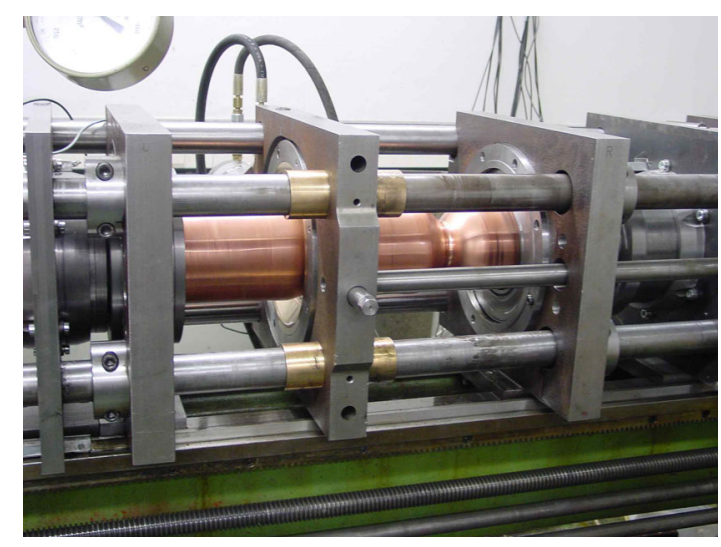

FIG. 9. Central part of DESY necking device.

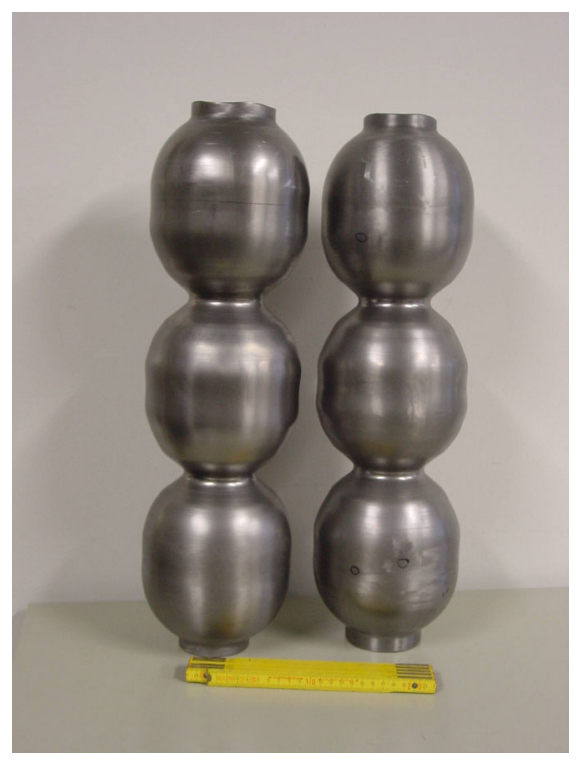

FIG. 10. Example of the $\mathrm{Nb}$ three-cell units after necking. 


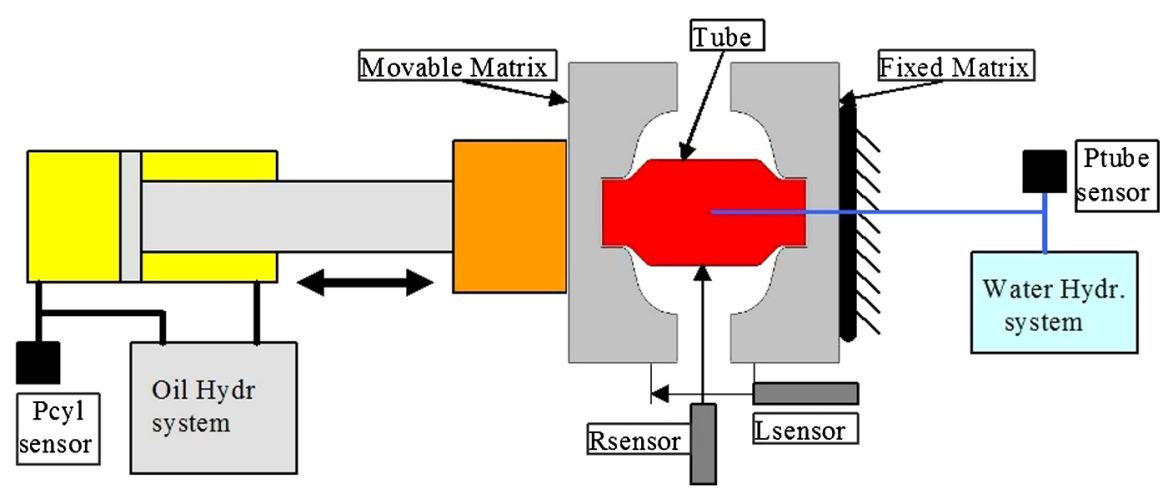

FIG. 11. Setup of the hydroforming machine at DESY.

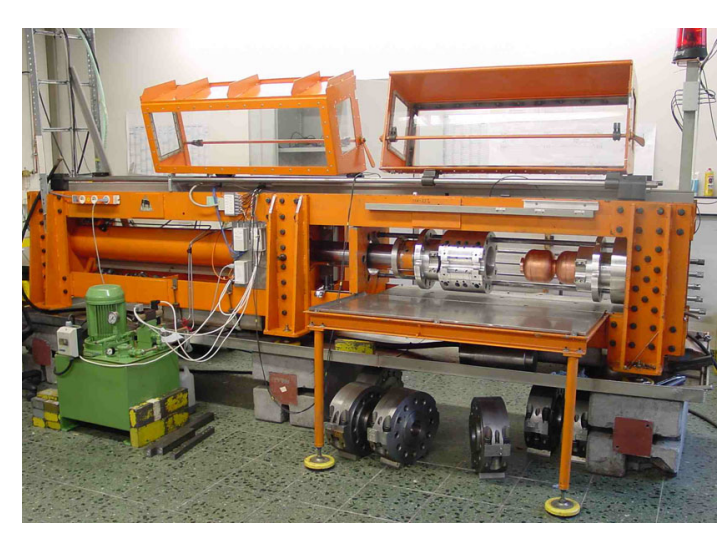

FIG. 12. The hydroforming machine.

At DESY the machine was equipped with a water hydraulic system for the internal pressure in the tube and with an oil hydraulic system for the cylinder movements to ensure the axial displacement.

The developed computer control system for the hydroforming permits one to perform the hydraulic expansion in a pulsed as well as in a continuous mode. Several sensors control the diameter growth of previously necked tube, the axial displacement, the water pressure in the tube and the oil pressure for the cylinder movement. The setup makes possible the application of a periodic stress fluctuation (pulse regime), as mentioned above.

The hydraulic expansion is based on the use of the correct relationship between internal pressure and axial displacement and assumes that the plastic limit of the material is not exceeded.

For the forming of a new type of tube the following strategy was applied for the hydraulic expansion: with the measured stress-strain characteristic of tube to be formed, the computer simulation of the hydroforming process is made. The forming process aims the smallest maximum strain in niobium at end of hydroforming. Further corrections of the expansion parameters are done by comparing the obtained by computer simulations and experimental growth of the tube diameter.

It is very important that the internal pressure to the tube is applied simultaneously with an axial displacement.

\section{First experiences and further development of the hydroforming procedure towards industrialization}

The FEM simulations assume that the mechanical properties of the tube are homogeneous. In reality the $\mathrm{Nb}$ tube has most of the time some local deviations in the grain size and the mechanical properties. Generally, during the start of the forming process such a tube will become plastic first at the location with the minimum of the yield (a)

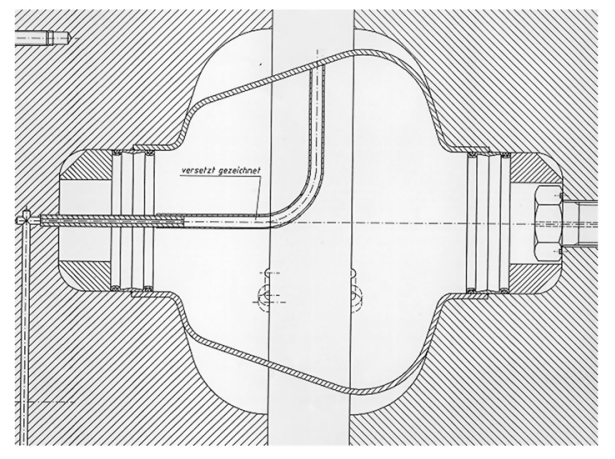

(b)

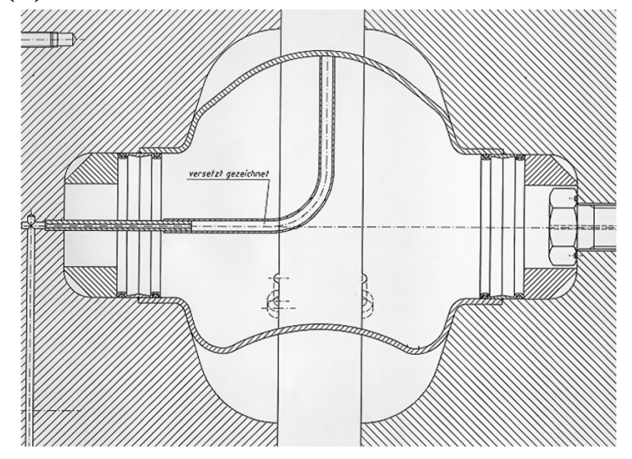

FIG. 13. (a) Conical anomaly of intermediate tube shape. (b) Anomalous tube shape for circumferential variation of yield strength. 


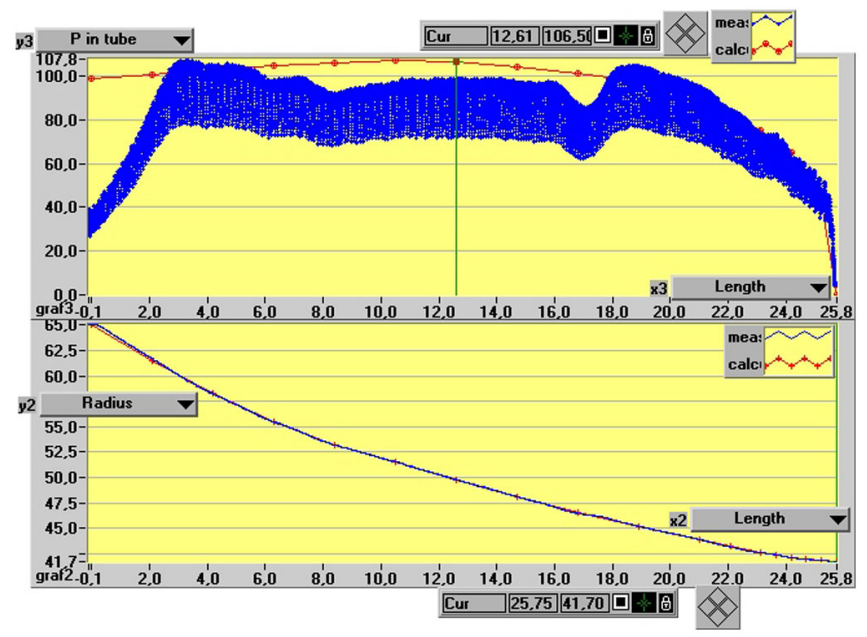

FIG. 14. Typical pressure vs axial displacement and radius vs axial displacement curves.

strength, which will result in local thinning of the wall and stress enhancement, producing more local deformation. This self-enforcing process will continue until fracture, unless it will be stopped either by strain hardening (weakly pronounced in $\mathrm{Nb}$ ) or by contact with the mould wall.

Two special situations have been observed [26].

If the yield strength of the tube monotonously varies from one end to the other, the tube will have a conical shape in the intermediate stage [Fig. 13(a)]. Tubes often show this feature, because many fabrication processes, like deep drawing or spinning, produce nonuniform deformations increasing from bottom to top. Accordingly, deviations of grain size and mechanical inhomogeneity are present after tube annealing.

Also random yield strength variation in the $\mathrm{Nb}$ tube can occur, such as variations of the yield strength along the tube circumference. In this case the formed tube looks like that shown in Fig. 13(b).

Both effects were present in varying degrees in the initial forming stage of the first monocells. As described below a lot of work was dedicated to the development of $\mathrm{Nb}$ seamless tubes with large elongation and uniform properties. Tubes with such characteristics permitted one to successfully form single cells and multicells of the TESLA shape even without intermediate constraint.

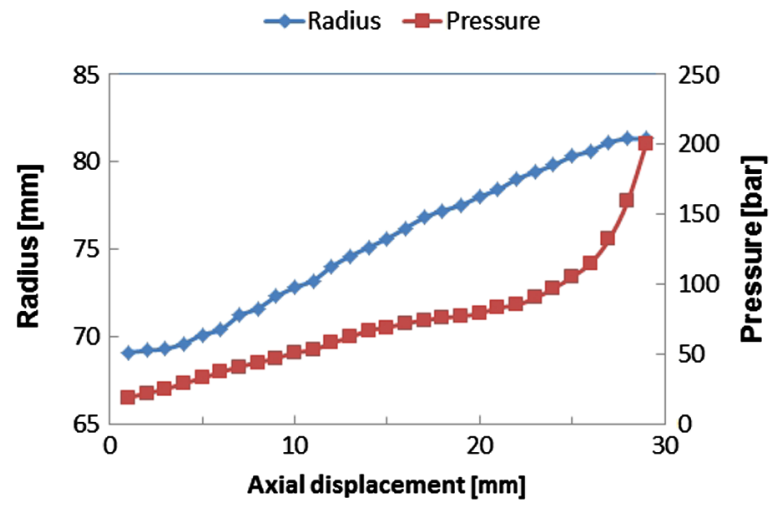

FIG. 16. Pressure and radius growth vs axial displacement on the first stage of the expansion.

The typical pressure vs axial displacement (gap between molds) and radius vs axial displacement curves are shown in Fig. 14. The water pressure for hydroforming of the niobium tube of $2.5-3 \mathrm{~mm}$ wall thickness is approximately $100 \mathrm{bar}$. As mentioned above, by variation the pressure (as it can be seen in Fig. 14) a radius increase in the range of plastic deformation without failure can be accomplished. The profile of the water pressure in the tube has three phases: growth of the pressure at the beginning of process, a medium section of nearly constant pressure and a reduction of the pressure at the end. This pressure profile produces monotonous growth of the tube radius.

In order to reduce the risk of failure and to adopt the procedure to serial production some further developments were needed.

It was determined to do the hydroforming in two stages in order to achieve the correct shape with rather uniform wall thickness of the complete cavity and to suppress instabilities in the tube expansion as mentioned above.

At the first stage of the expansion the necked tube reaches roughly a medium value between initial and a final diameter: the tube expands until it touches the specially shaped mould (intermediate constraint). This mould shape is chosen as the result of FEM simulation (Fig. 15). The first stage consists of two steps schematically shown in Fig. 16: in the first step the radius grows monotonously until the tube touches the mould at the equator; in the second step the pressure increases significantly in order to

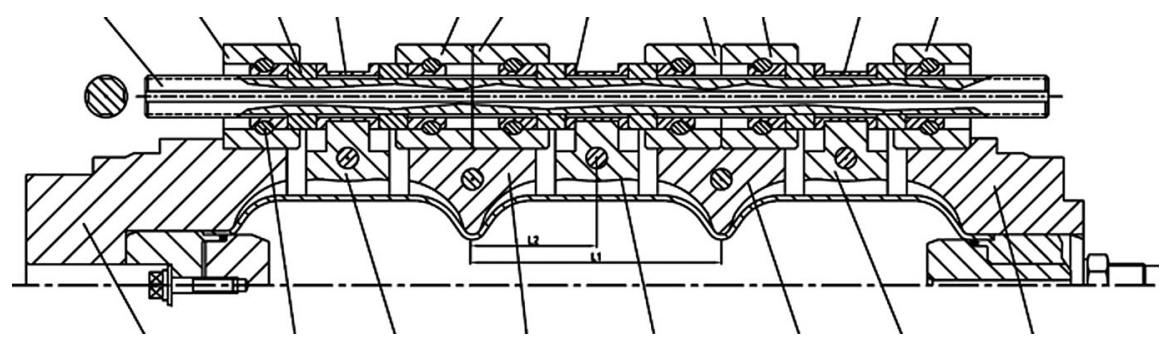

FIG. 15. Shape of the intermediate constraint. 


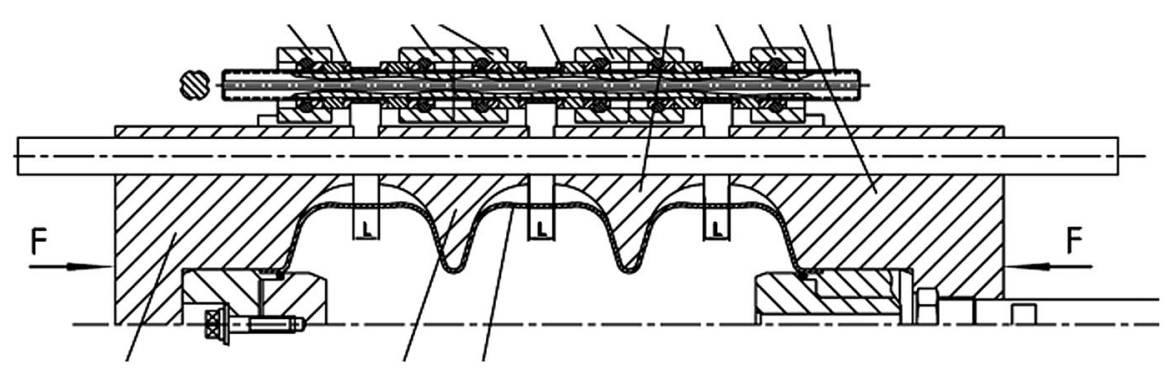

FIG. 17. Shape of the molds for final forming.

perform the expansion in the area between the equator and iris.

At the second stage the final expansion into the external mould with the final cavity shape takes place (Fig. 17). In order to get monotonous growth of tube radius during hydroforming and not to exceed the plastic limit of the material, the pressure should be kept close to constant after reaching the required value for the onset of plastic flow (Fig. 18).

A special mechanism synchronizes the movement of the molds and allows stable forming of many cells simultaneously. The synchronization is relevant for both stages of expansion. The principle of the synchronization is described in detail in the patent [23] and can be derived from Figs. 15 and 17.

\section{High pressure calibration of hydroformed cavities}

A calibration device with strengthened matrices has been designed and constructed. The purpose of the gadget is to achieve a gap-free contact of cavity walls with the mould everywhere, especially in the iris region, which is most difficult for hydroforming. The device consists of matrices from 7075 T6 aluminum alloy supported by a massive steel tube. It can sustain pressures up to 1000 bar and can be used to calibrate resonators with one to nine cells (Figs. 19 and 20).

High pressure calibration matches the outside shape of the cells precisely to the shape of the mould. This is

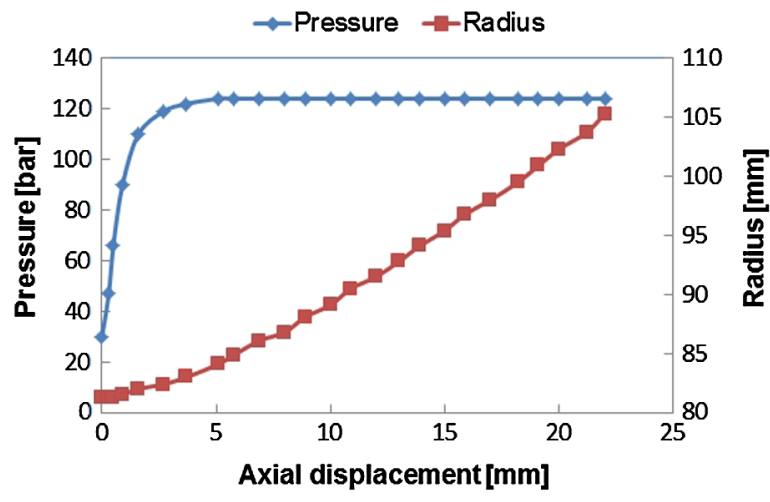

FIG. 18. Pressure and radius growth vs the axial displacement on the second stage of the expansion. possible because of the relatively high spring back of the mould and the relatively low yield strength of the $\mathrm{Nb}$.

With increasing pressure the cavity will grow plastically with the mould, which remains elastic. When pressure is released the mould springs back to its initial stress-free form. At the same time, the resonator will be slightly squeezed plastically to the shape of the mould. This procedure can provide a resonator with high shape accuracy and a straight axis.

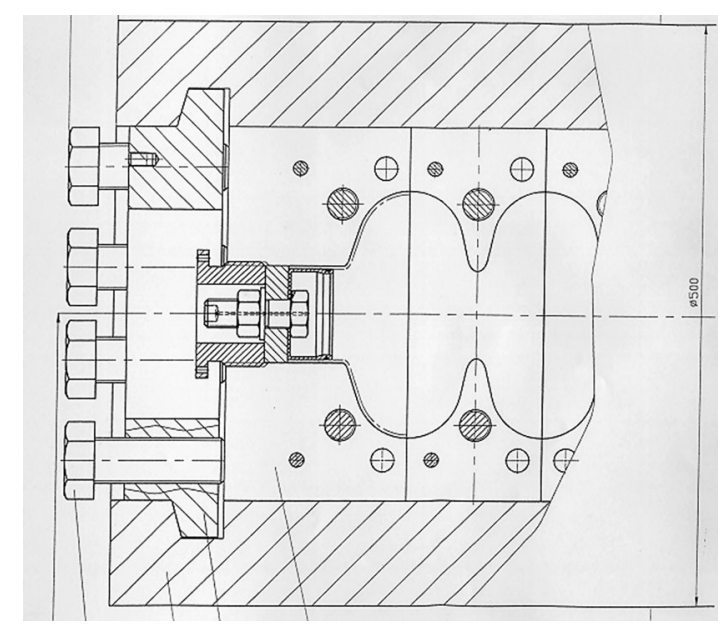

FIG. 19. Schema of high pressure calibration device.

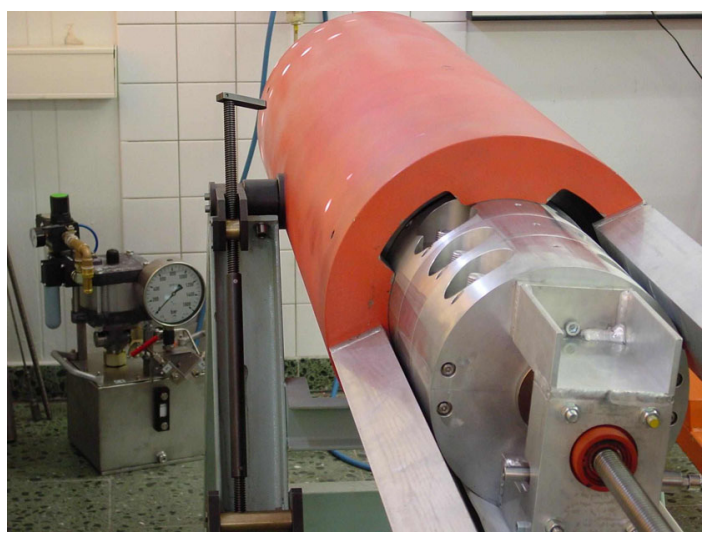

FIG. 20. DESY calibration device for hydroformed cavities. 


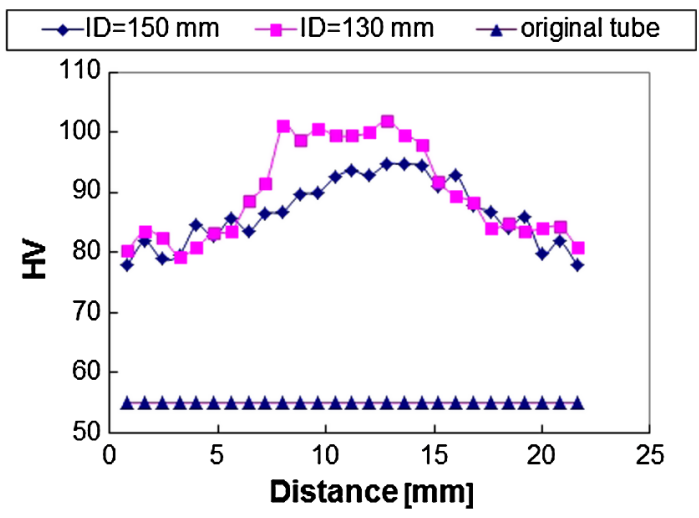

FIG. 21. Vickers hardness HV along the cell contourstarting from the iris. Cells are hydroformed from tubes of ID $=130 \mathrm{~mm}$ and ID $=150 \mathrm{~mm}$. Straight line represents the $\mathrm{HV}$ of the original tube.

\section{DEVELOPMENT OF NIOBIUM SEAMLESS TUBES FOR HYDROFORMING}

The development of the fabrication of niobium tubes with satisfactory properties is challenging and significantly affected our progress in a similar way as the development of the hydroforming procedure. The tube has to fulfill several requirements: high purity (RRR close to 300), high and uniform elongation before local thinning $(>25 \%$ in the worst case), low anisotropy, tight dimensional tolerances for the wall thickness (within $\pm 0.1-0.2 \mathrm{~mm}$ ) and high surface quality.

In addition, the optimal tube diameter for hydroforming had to be determined. The TESLA shape cavity has an equator inside diameter $\mathrm{ID}=206.6 \mathrm{~mm}$ and the iris $\mathrm{ID}=70 \mathrm{~mm}$. For the choice of the initial tube diameter, two aspects had to be considered.

(i) The strain at the equator should remain during the expansion below the onset of the material local thinning. Therefore, a larger initial tube diameter is preferred, easing the second stage of hydroforming.

(ii) On the other hand an enlargement of the tube diameter increases the thinning of the tube wall in the iris region during necking.

First estimations and experiments have shown that for high purity niobium, a tube ID between 130 and $150 \mathrm{~mm}$ is close to optimal. The TESLA shape cells have been successfully fabricated starting both from ID $=130 \mathrm{~mm}$ and $\mathrm{ID}=150 \mathrm{~mm}$. However, a measurement of the
Vickers hardness (HV) distribution (by load $10 \mathrm{~N}$ ) of the hydroformed cells (Fig. 21) allows one to conclude that the work hardening of the tube with ID $=130 \mathrm{~mm}$ at the equator is rather high and presumably not far away from the rupture limit ( $\mathrm{HV}$ of the cold rolled $\mathrm{Nb}$ for example is ca. 110).

As shown in Fig. 21, a reduction of the tube diameter increases the work hardening at the equator region and has a smaller influence at the iris area.

Therefore, the ID $=150 \mathrm{~mm}$ is more preferable for hydroforming of TESLA shape cavities. After successful improvement of the necking procedure only tubes with $\mathrm{ID}=150 \mathrm{~mm}$ have been used for hydroforming.

To find a suitable production method for seamless tubing with the desired properties for hydroforming several production techniques have been examined: (i) shaping of a sheet to tube and welding; (ii) backward extrusion; (iii) spinning; (iv) deep drawing; (v) flow forming; (vi) forward extrusion; and (vii) bimetallic tubes (see Sec. VII).

Initially the welded option was explored. The bulge test performed on a disk with the diametric EBW seams indicated insufficient elongation before local thinning (below 20\%). The rapture location was usually at the heat affected zone (HAZ). This behavior could be predicted since the EBW microstructure of Nb (Fig. 22) shows big irregularity of the grain size in the welding seam and in the HAZ. Theoretically this grain size can be reduced by deformation (local rolling) of the welding seam area and subsequent annealing. In the practice however, it is difficult to implement the procedure for high purity $\mathrm{Nb}$ due to high degree of deformation ( $>65 \%$ ) needed to establish small and uniform grains [27].

The shaping of small tubes directly from ingot fraction by back extrusion [28] was developed at the company WC HERAEUS for components for the light bulb industry. This technique seems to be cost effective. $\mathrm{Nb}$ tubes with $\mathrm{RRR}=300(\mathrm{Nb} 300)$ of appropriate diameters for hydroforming have been produced at WC HERAEUS for DESY. Unfortunately, first attempts have shown that these tubes are not applicable for hydroforming of TESLA shape cells. The tubes burst at the initial or middle stage of hydroforming. The analysis of the microstructure has shown a big scattering in the grain size from surface to the middle of the wall and in the circumference [29]. Irregularities from small $(50-100 \mu \mathrm{m})$ to rather big grains $(500-1000 \mu \mathrm{m})$ (see Fig. 23) reduce the elongation before local thinning

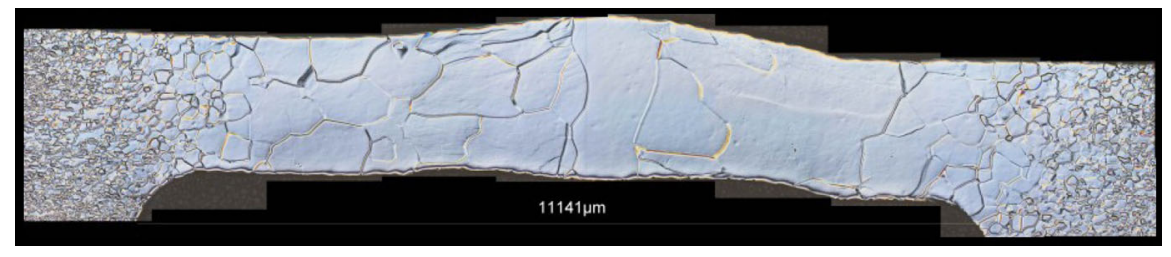

FIG. 22. Microstructure of the electron beam weld of high purity niobium. The grain size scope is 50-2000 $\mu \mathrm{m}$. 


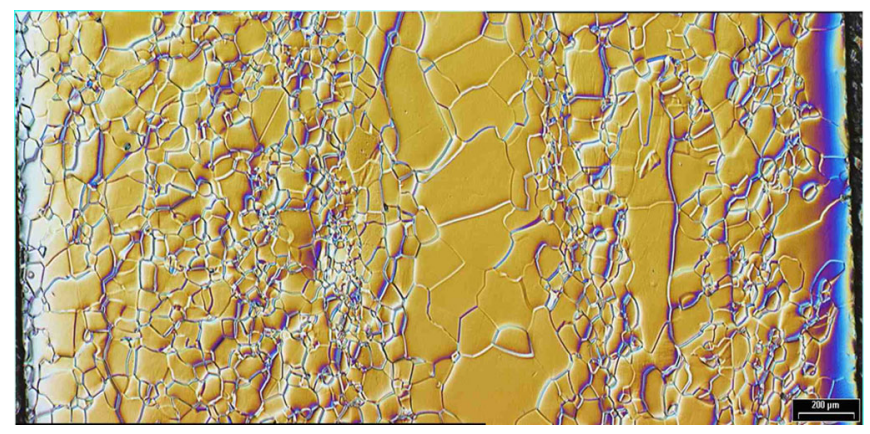

FIG. 23. Microstructure of the back extruded niobium tube with RRR300.

and yield a rough inside surface after hydroforming. It seemed that the degree of deformation of this technique is not sufficient to reduce the large grain size $(\mathrm{a}$ few $\mathrm{cm}$ ) of the ingot material to the necessary small and uniform grains of approximately $100 \mu \mathrm{m}$ size in the final tube after annealing $[27,30,31]$.

Further efforts have shown that satisfactory results can be achieved, if one starts with thick niobium sheet, which is commercially available. The tubes can be produced by deep drawing or spinning [28]. Such tubes show acceptable elongation before onset of local thinning. Particularly successful is the combination of spinning or deep drawing with flow forming [28]. Flow forming over a cylindrical mandrel has gained more importance in the past years. Machines with three work rollers accomplishing the flow forming in either forward or reverse direction are available. This method allows the production of very precise tubes from spun or deep drawn thick walled cylindrical parts. The ratio of the length to diameter can exceed 20 , the ratio of diameter to wall thickness can exceed 500 for such tubes. The flow forming of high purity $\mathrm{Nb}$ tubes was developed at a German company-Metall Specialrohr MSR. After optimization of the process parameters, shiny surfaces and small wall thickness variations (less then $\pm 0.1 \mathrm{~mm}$ ) could be achieved.
In cooperation with industry the seamless tubes have been fabricated from $10 \mathrm{~mm}$ thick niobium sheet with rather small and uniform grain structure by spinning at Co. Thate, Germany [Figs. 24(a) and 24(b)] and subsequent forward flow forming at Co. MSR [Figs. 25(a) and 25(b)]. By these techniques tubes of a length up to $950 \mathrm{~mm}$ with wall thickness tolerances of $\pm 0.15 \mathrm{~mm}$ have been produced.

The microstructure and crystal orientation was not ideal for deformations. As it can be seen in Fig. 26 grain size is not completely uniform (some increased grains close to the inside surface are visible), random distribution of crystal orientation (suitable in our case) is not completely present. Anisotropy of the mechanical properties was still significantly pronounced as our tensile tests have shown. The smallest values of elongation before local thinning - about 27\%-35\% - were observed in the circumferential directions; however they were acceptable for our goal [32]. From these tubes single-, double- and three-cell units were formed, which as reported below, ensured high cavity performance. However, these tubes were not long enough to form a nine-cell cavity from a single piece.

Finally, seamless tubes of a sufficient length for ILC type nine-cell cavities have been developed in cooperation between two companies-Black Laboratories and Wah Chang BL-WC - based on forward extrusion and flow forming [33]. A billet was heavily deformed to produce a fine grain structure and after subsequent recrystallization a fine grain, weakly textured tube of $1.65 \mathrm{~m}$ length and $3 \mathrm{~mm}$ wall thickness was extruded. Such extruded tubes has been successfully formed with DESY's hydroforming equipment [33]. Several two-cell and three-cell units were produced at DESY (Fig. 27).

It turned out as a remaining important issue that a compromise between surface roughness of the hydroformed cells and grain size has to be found. The tubes processed for minimal surface roughness (smaller than DESY tubes) exhibited too small grains (ca. $20 \mu \mathrm{m}$ ), in some locations surpassed the ductility limit. (a)

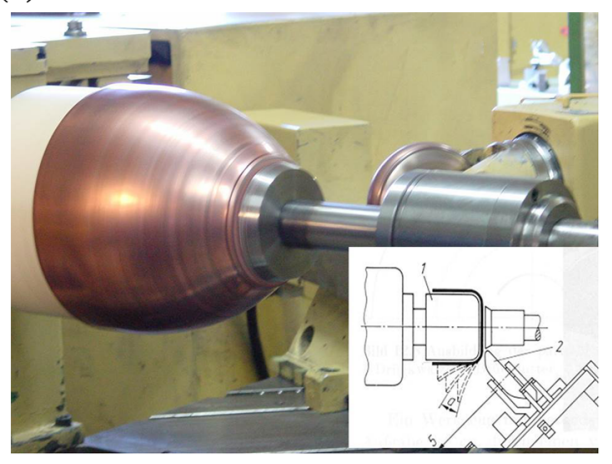

(b)

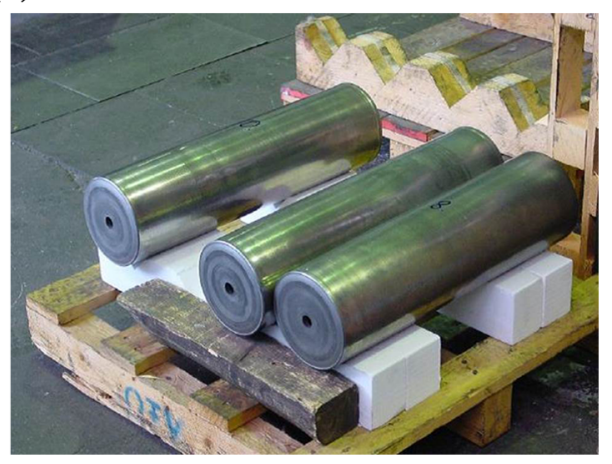

FIG. 24. (a) Spinning process. (b) Spun Nb tubes. 
(a)

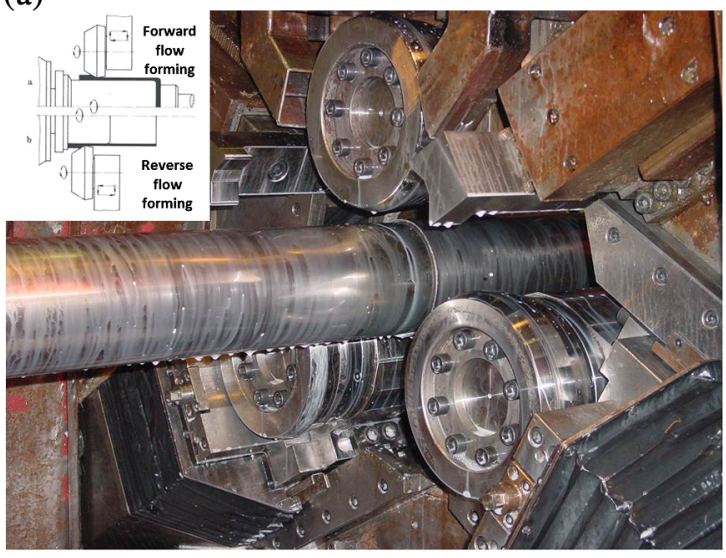

(b)

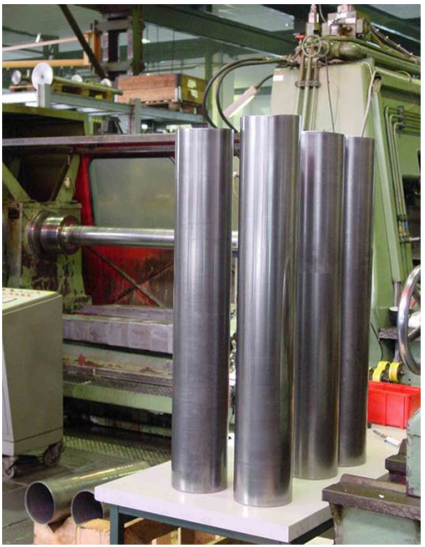

FIG. 25. (a) Flow forming process. (b) Subsequently flow formed spun $\mathrm{Nb}$ tubes.
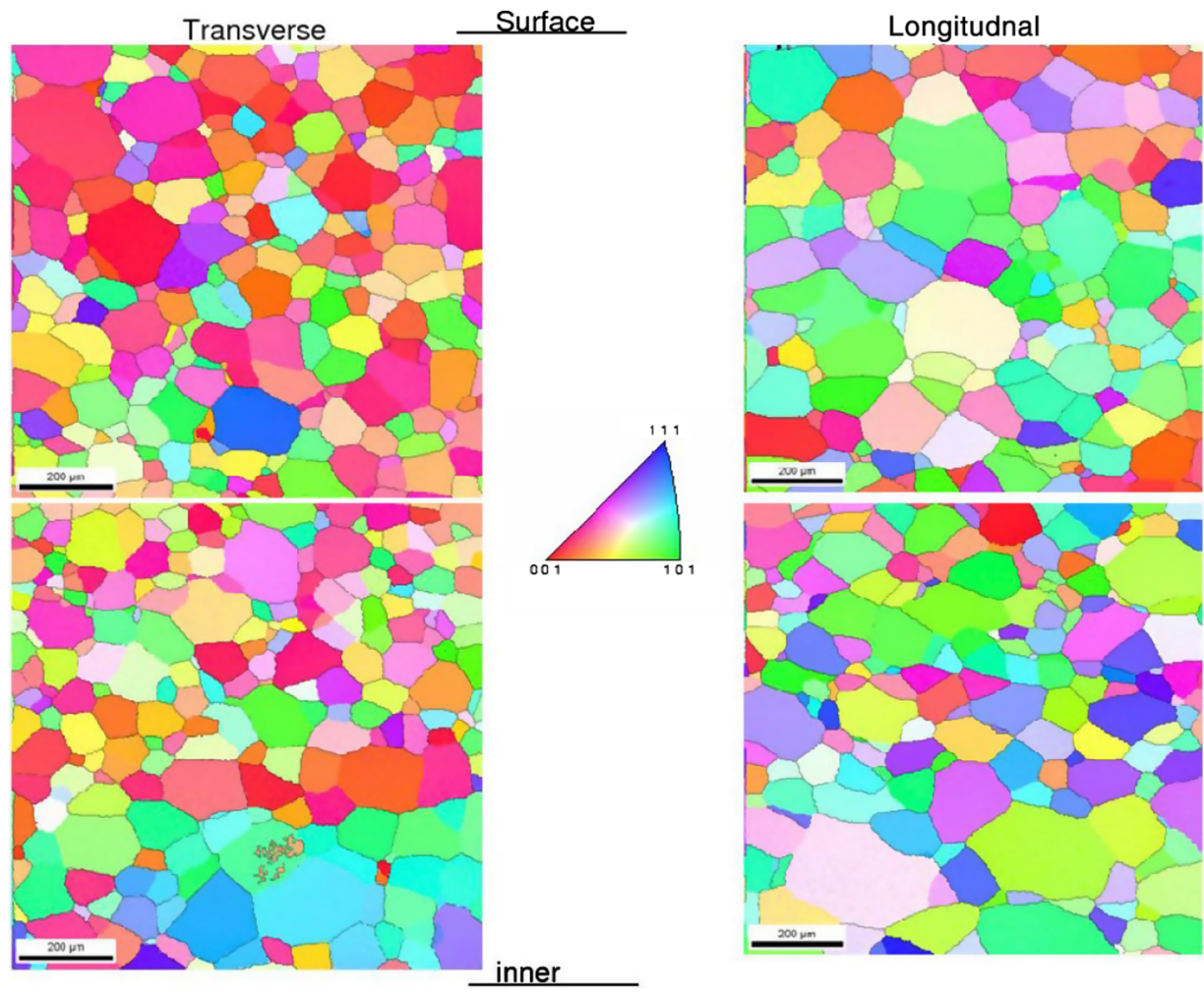

FIG. 26. Orientation Imaging microscope figures of the $\mathrm{Nb}$ tube produced by combination of spinning and flow forming.

Advantages and disadvantages of niobium seamless tube production methods are listed in Table I.

\section{BULK NB CAVITIES}

\section{A. Single-cell cavities}

Several single-cell cavities have been manufactured without intermediate annealing from spun or deep drawn tubes with ID 130 or $150 \mathrm{~mm}$. As mentioned above, the forming was possible without intermediate constraint.

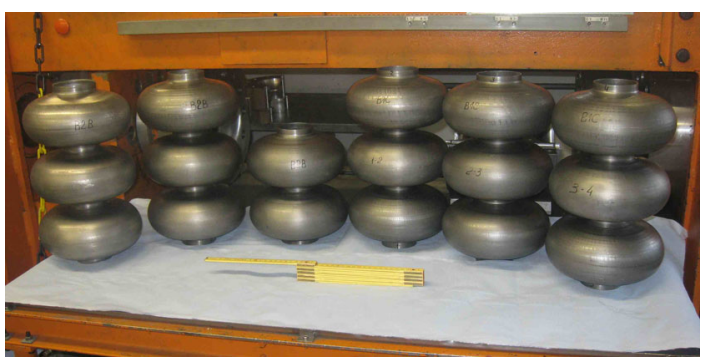

FIG. 27. Three- and two-cell units, hydroformed from BL-WC tubing. 
TABLE I. Comparison of acceptable methods of seamless tube fabrication.

\begin{tabular}{|c|c|c|}
\hline Procedure & Advantages & Disadvantages \\
\hline Deep drawing from sheet & Weak anisotropy of mechanical properties & Relatively high wall thickness variation \\
\hline Spinning from sheet & Weak anisotropy of mechanical properties & Relatively high wall thickness variation \\
\hline Backward extrusion from ingot pill & Few production steps (ingot-pill-tube), cost effective & e Not sufficient mechanical properties \\
\hline $\begin{array}{l}\text { Combination of spinning and flow } \\
\text { forming }\end{array}$ & $\begin{array}{c}\text { Tight wall thickness tolerances of } \pm 0.1 \mathrm{~mm} \\
\text { reachable }\end{array}$ & $\begin{array}{l}\text { Not sufficient length for nine-cell } \\
\text { cavity }\end{array}$ \\
\hline
\end{tabular}

Finally the cavities were calibrated by increasing the internal pressure up to 500 bar.

In order to confirm a proof of principle the hydroformed cavities have been treated similar to the conventional welded cavities and the performances was compared.

Three types of surface treatment were explored: buffered chemical polishing (BCP); BCP together with post purification using Ti; EP with subsequent baking at ca. $120^{\circ} \mathrm{C}$ and some combinations of these procedures. In all cases, the high pressure water rinsing (HPR) was applied additionally.

The maximum accelerating gradients of hydroformed single-cell cavities treated by BCP only are summarized in Fig. 28. The average $E_{\text {acc }}=28 \mathrm{MV} / \mathrm{m}$. The results seem to indicate that seamless cavities-after sufficient BCP (removal the surface layer of 150-250 $\mu \mathrm{m}$ ) - are performing even better than welded cavities treated similarly. The average max $E_{\text {acc }}$ of BCP treated welded cavities is $24 \mathrm{MV} / \mathrm{m}$ [34].

Several outstanding results have been achieved mostly by applying EP. One of the best results of a hydroformed bulk Nb single-cell cavity is shown in Fig. 29 [35]. Cavity $1 \mathrm{~K} 2$ demonstrates an accelerating field of $\geq 42 \mathrm{MV} / \mathrm{m}$ and a high $Q$-value of $>1.5 \times 10^{10}$ at the highest $E_{\text {acc }}$.

The measured accelerating field of $E_{\text {acc }} \geq 42 \mathrm{MV} / \mathrm{m}$ in this cavity is among the highest ever achieved with a single cell. Surprisingly, the cavity behavior did not change significantly over a period of 15 years and the surface seems to be quite stable and resilient [36].

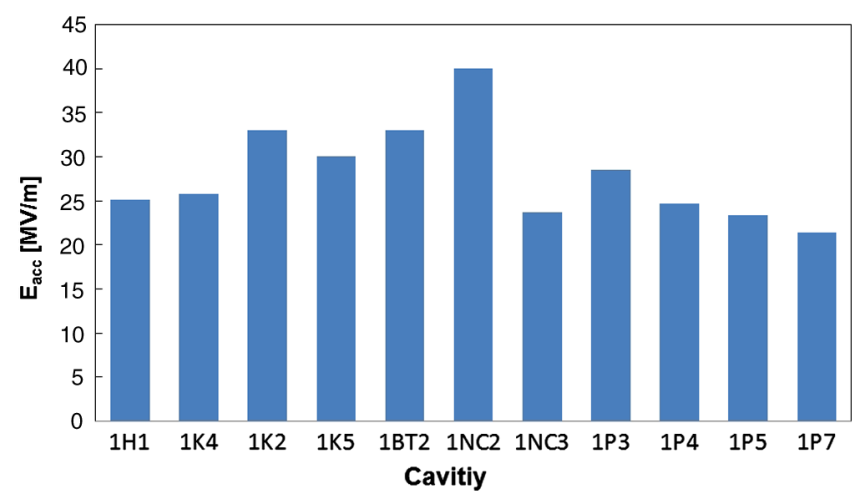

FIG. 28. Maximal accelerating gradients of BCP treated singlecell hydroformed cavities.

\section{B. Hydroforming of multicells}

One of the important next steps of the seamless development was to successfully extend the technology to multicell cavities.

The main problem in the multicell fabrication was the reduction of the tube diameter in the iris area between two cells (necking). In the first stage of the development the necking was done by spinning using an industrially available spinning machine and a "teach and playback" procedure. For single-cell cavities requiring only short tubes and necking at only the end tube, this procedure is successful. This technique was less successful for the longer tubes, because it was difficult to achieve the uniform wall thickness at the necking area. The irregularity in the wall thickness of up to 1-2 $\mathrm{mm}$ at the iris area produced sometimes holes during material removal by BCP, EP or centrifugal barrel polishing. The situation was decisively improved by development of a special necking procedure (described above). The wall thickness tolerances remained at $\pm 0.2 \mathrm{~mm}$ for necked of three- and two-cell units.

Several double- and three-cell bulk $\mathrm{Nb}$ cavities of the TESLA shape were successfully hydroformed at DESY. Although the forming was possible without intermediate constraint, an intermediate constraint was applied in order to reach stable and reproducible cavity fabrication.

Theoretically, the expansion at the equator area can be done either simultaneously for all cells or successively one cell after the other. The second option is preferable for hydroforming of a nine-cell cavity from a single tube. The fabrication is more reliable this way, even if some variation of the plastic properties within the tube is present. Both

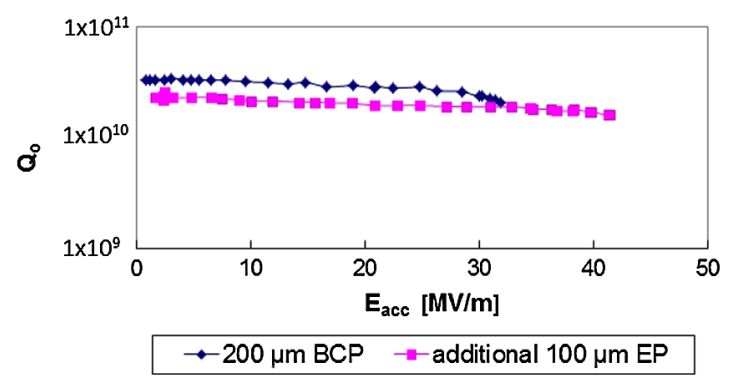

FIG. 29. $Q_{\mathrm{o}}$ vs $E_{\text {acc }}$ at $2 \mathrm{~K}$ for cavity $1 \mathrm{~K} 2$ produced from deep drawn tube after BCP and final EP. RRR100, post purified at $1400{ }^{\circ} \mathrm{C}$. BCP and rf tests done at JLab. EP done at KEK [35]. 
options were demonstrated with copper tubing (see Fig. 30) and successfully realized on $\mathrm{Nb}$ three-cell units. Examples of hydroformed two- and three-cell units are shown in Fig. 31.

Typically, hydroforming produces rougher surface finishes than deep drawing, because of the higher degree of deformation (25\% for hydroforming, 10\%-15\% for deep drawing). The roughness just after forming also depends on the tube production procedure.

However, very rough surfaces in the welding areas, which do not completely disappear even after 150-200 $\mu \mathrm{m}$ of EP, are absent in hydroformed cavities. Centrifugal barrel polishing (CBP) seems to be a reasonable process for hydroformed cavities. In some cases CBP [37] was applied.

A summary of preparation and rf test results from six double-cell cavities carried out at JLab can be found in Ref. [38]. Typically, after approximately 100-200 $\mu \mathrm{m}$ material removal by $\mathrm{BCP}$, the cavities are reaching $E_{\text {acc }}$ of $25-30 \mathrm{MV} / \mathrm{m}$. Additional EP treatment with baking at ca. $120^{\circ} \mathrm{C}$ increases $E_{\text {acc }}$ up to $35-38 \mathrm{MV} / \mathrm{m}$. The $Q_{\text {o }}$

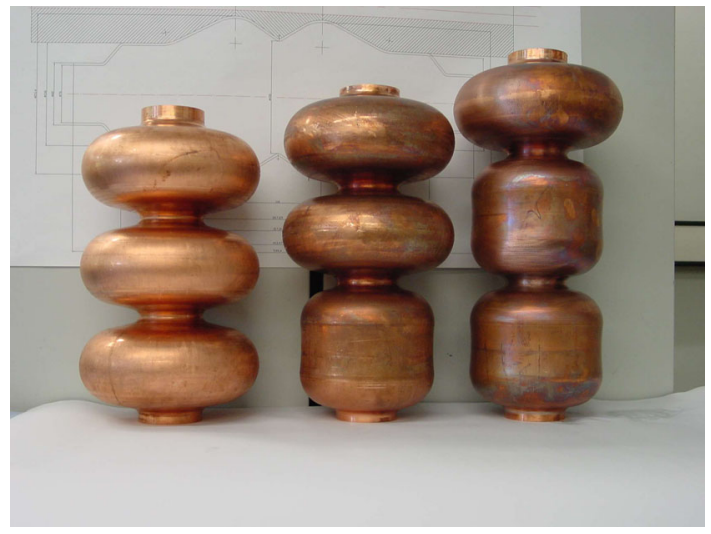

FIG. 30. Hydroforming of cells can be done by three cells simultaneously as well as cell by cell.

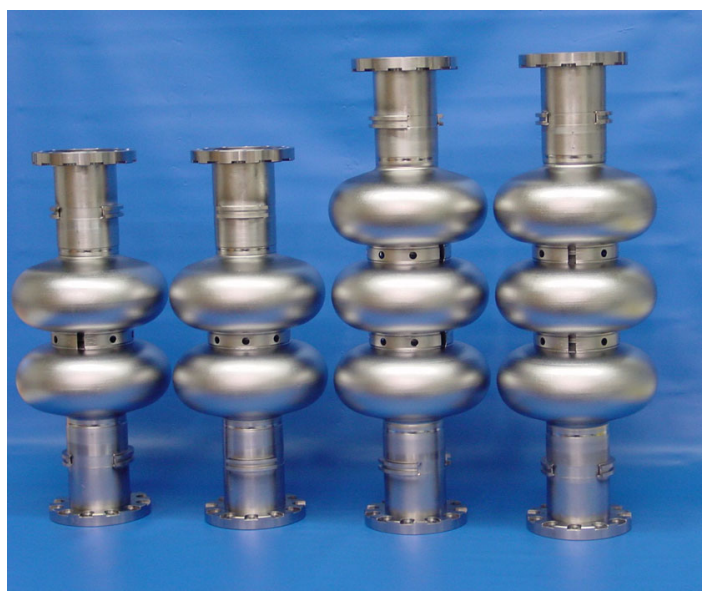

FIG. 31. Two- and three-cell cavities hydroformed at DESY.

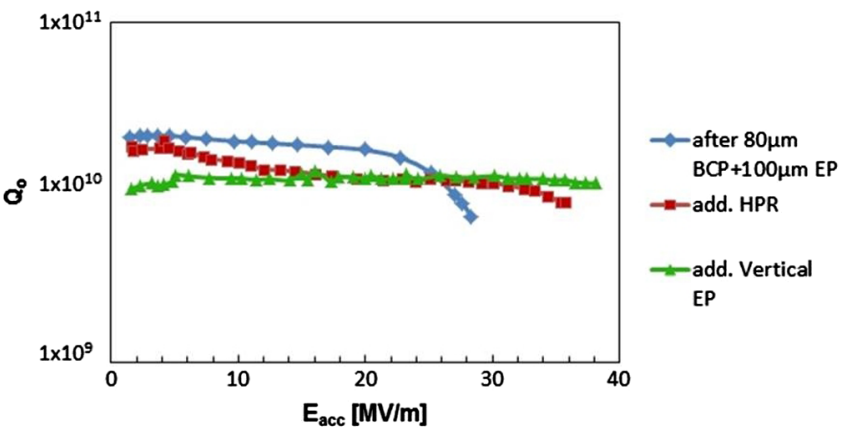

FIG. 32. $Q_{\mathrm{o}}$ (Eacc) performance of the two-cell hydroformed cavity 2H3. Vertical EP done at Cornell University by A. Crawford.

$\left(E_{\text {acc }}\right)$ curve of the best double-cell cavity is shown in Fig. 32.

The three-cell units were hydroformed for assembly into nine-cell cavities from tubes with RRR values of 250-300, a diameter of $150 \mathrm{~mm}$ and a wall thickness of $2.7 \mathrm{~mm}$. The cells were formed simultaneously in two stages with an intermediate constraint. Three of them (for the cavity Z164 in future) have been treated and rf tested at JLab $[39,40]$. After the hydroforming was completed, the three three-cell units were centrifugal barrel polished at DESY removing approximately $100 \mu \mathrm{m}$. A stress relieving annealing step at $600^{\circ} \mathrm{C}$ for $10 \mathrm{~h}$ in high vacuum after about $100 \mu \mathrm{m}$ of material removal by BCP at JLab softened the cavities appropriately and tuning could be accomplished.

Figure 33 summarizes the cavity performance after a postpurification heat treatment at $1250{ }^{\circ} \mathrm{C}$ for $3 \mathrm{~h}$ in a Ti box. None of the cavities was limited by a "quench," but rather by a degradation of the $Q_{0}$-value (" $Q$-drop") in the absence of field emission at accelerating gradients of $E_{\text {acc }}=32-35 \mathrm{MV} / \mathrm{m}$.

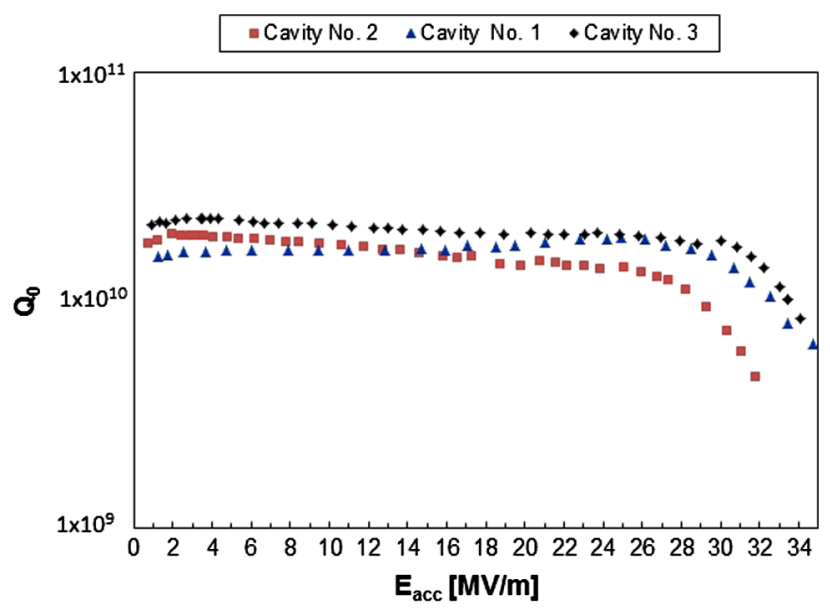

FIG. 33. $Q_{\mathrm{o}}\left(E_{\mathrm{acc}}\right)$ of three-cell hydroformed cavities after post purification at $1250{ }^{\circ} \mathrm{C}$. The total material removal is ca. $250 \mu \mathrm{m}$ by BCP. 
(a)

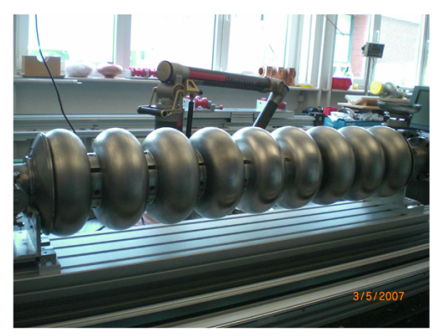

(b)

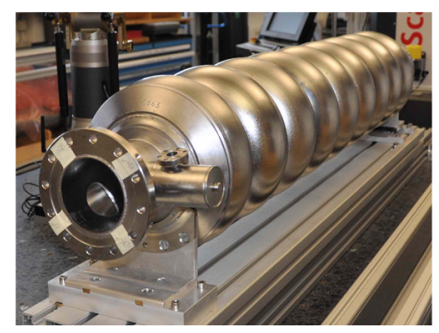

(c)

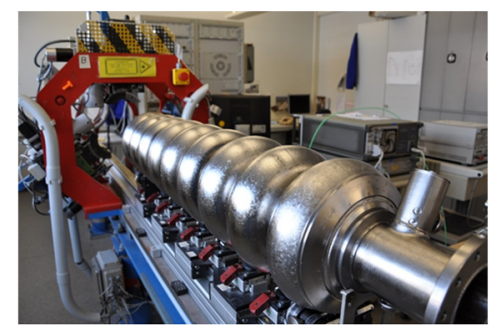

FIG. 34. Hydroformed nine-cell TESLA cavities Z145, Z163 and Z164 from left to the right.

JLab's two-cell $T$-mapping system was assembled on the top and bottom cells of cavity \#1 representing top and bottom of the initial tube. The $T$-maps show several "hot spots" in the equator (high magnetic field) region of both cells, although they appear to be more intense in the top cell. This feature might be a result of the tube fabrication method: during the spinning the top of the tube experiences the largest deformation and the outside and inside surfaces receive the most surface damage; these surfaces are visibly rough with tiny cracks.

\section{Fabrication of nine-cell hydroformed cavities}

The final goal of the hydroforming development was the fabrication of nine-cell cavities of the TESLA shape. As mentioned above the DESY hydroforming machine was built as a prototype to develop the feasibility of the hydroforming technique. Dimensionally, it can produce only three-cell units and nine-cell cavities have to be assembled from three three-cell parts. There are no technical obstacles to extend the hydroforming procedure to nine-cell cavity fabrication from a single tube especially since a cell-by-cell manufacturing was proven.

The three-cell units were combined to nine-cell cavities at company E. Zanon.

Completing included the following steps: (i) fabrication of the long and short end groups connected with proper three-cell units; (ii) machining, weld preparation and EBW of two iris welds (from outside) to complete a nine-cell cavity; and (iii) machining, preparation and attaching the stiffening rings by EBW.

In total three nine-cell cavities (Z145, Z163 and Z164) were fabricated (see Fig. 34). The cavity Z164 was completed from three cell units investigated previously at JLab (described above).

Originally, the molds for hydroforming have been calculated and built for tubes with a wall thickness of $3 \mathrm{~mm}$. The tubes used, however, were $2.7 \mathrm{~mm}$ thick. Therefore, after hydroforming the inside volume was larger and accordingly the resonant frequency was lower as planned. The conventional tuning procedure as described in Ref. [41] had to be modified to avoid excessive lengthening of the cavity during the first rough tuning step. Instead of tuning by lengthening, the cells were deformed radially. A roller, with the profile close to the cell shape at the equator area, moves radially in relation to rotating cavity (see Fig. 35). A reduction of the cell radius by $0.2-0.8 \mathrm{~mm}$ changed the frequency easily by $1-2 \mathrm{MHz}$. Afterwards, final tuning was accomplished with DESY's standard tuning machine [41] and well-known tuning procedure. For example the field flatness of cavity Z163 after radial pretuning was $88 \%$, after subsequent standard tuning $99 \%$.

Prior to tuning the cavities have been "softened" by a $800^{\circ} \mathrm{C}$ annealing after removal of $40 \mu \mathrm{m}$ by BCP.

Radial tuning can be applied to any cavities, if the frequency has lowered too much because of excessive material removal (approximately $>500 \mu \mathrm{m}$ ); it prevents a length increase from conventional tuning out of tolerance $( \pm 3 \mathrm{~mm})$.

Cavities Z145 and Z163 have been rf tested at DESY after surface treatment of ca. $150 \mu \mathrm{m} \mathrm{EP}$, ethanol rinsing, $800^{\circ} \mathrm{C}$ heat treatment, $50 \mu \mathrm{m} \mathrm{EP,} \mathrm{HPR} \mathrm{and} \mathrm{baking} \mathrm{at}$ $120^{\circ} \mathrm{C}$ for $48 \mathrm{~h}$.

Cavity Z145 reached a maximum accelerating gradient of approximately $30 \mathrm{MV} / \mathrm{m}$, maximum $E_{\text {acc }}$ for cavity $\mathrm{Z} 163$ was about $35 \mathrm{MV} / \mathrm{m}$. In both cases the $Q_{\mathrm{o}}$ at the highest gradients exceeded $10^{10}$.

Passband mode measurements showed that individual cells had gradients between 30 and $39 \mathrm{MV} / \mathrm{m}$.

The performance of these two nine-cell cavities is shown in Fig. 36 (for Z145 at 2K, and for Z163 at $2 \mathrm{~K}$ and $1.8 \mathrm{~K})$.

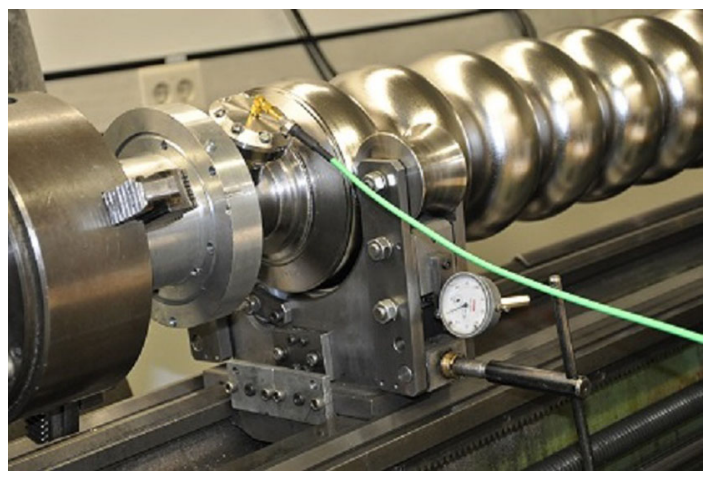

FIG. 35. Radial tuning of the cavity Z163. 


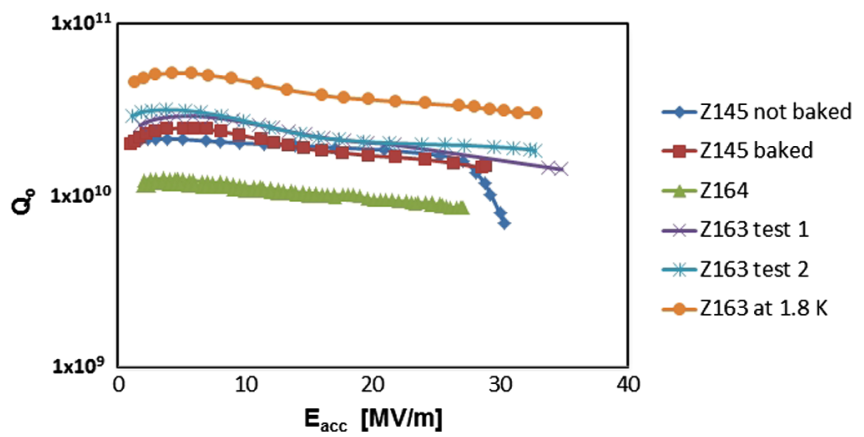

FIG. 36. Radio-frequency performance of nine-cell hydroformed cavities Z145, Z163 and Z164.

Cavity Z164 went through four cycles of surface treatment and five rf tests, all performed at $2 \mathrm{~K}$ at JLab [42]. Initially after the first $50 \mu \mathrm{m} \mathrm{BCP}$ and high temperature heat treatment at $800^{\circ} \mathrm{C}$ the cavity was limited at $27 \mathrm{MV} / \mathrm{m}$ (Fig. 36). After a $30 \mu \mathrm{m}$ of EP and a low temperature bake $\left(120^{\circ} \mathrm{C}\right.$ for 48 hours) the cavity degraded to a quench field of $18 \mathrm{MV} / \mathrm{m}$ with moderate field emission. A subsequent EP of $20 \mu \mathrm{m}$ followed by ethanol rinse only slightly improved the cavity performance to $21 \mathrm{MV} / \mathrm{m}$. During the last rf test, passband measurements suggested the quench location in cell 4 or 6 . Both $T$-mapping and the use of triangulated second sound sensors pointed to the lower half-cell \#4 approximately $25 \mathrm{~mm}$ away from the equator as the single quench location. An extensive optical inspection on and around the quench area could not identify any defect.

This rather low accelerating gradient of the cavity is unexpected because all three three-cell units had performed well up to gradients of $32-35 \mathrm{MV} / \mathrm{m}$ (see Fig. 33). It can be speculated that defects were introduced during the completion process for this cavity.

\section{HYDROFORMING OF NBCU CLAD CAVITIES}

The hydroforming technique can also be applied to seamless bimetallic tubes $[22,43,44]$. This option opens new opportunities for cost savings and performance improvements. The material combination of clad, thin niobium ( 0.5 to $1 \mathrm{~mm}$ thickness) on $2-3 \mathrm{~mm}$ thick copper saves material costs for the expensive niobium and increases the thermal stability of the cavity against quench due to the high thermal conductivity of copper.

Additionally, cladding permits to retain almost all treatment procedures applied to bulk $\mathrm{Nb}$ such as $\mathrm{BCP}$, $\mathrm{EP}$, annealing at $800^{\circ} \mathrm{C}$, in situ baking at $120^{\circ} \mathrm{C}$, HPR and CBP. Thin film deposition [45] is lacking these advantages. In addition, stiffening against Lorentz force detuning can easily be done by increasing the thickness of the $\mathrm{Cu}$ layer.

\section{A. Fabrication of seamless $\mathrm{NbCu}$ clad tubes}

Fabrication of seamless $\mathrm{NbCu}$ clad tubes is, as well as for bulk niobium tubes, a subject of special efforts. Requirements to mechanical properties of niobium component are not so challenging in this case because the plastic properties of $\mathrm{Cu}$ have a dominant role during hydroforming.

Even the mechanical properties of back extruded seamless $\mathrm{Nb}$ tubes of inhomogeneous grain structure can be tolerated. The main challenge is to produce high quality of $\mathrm{Nb}$ without reduction of its purity in the clad configuration.

Different cladding procedures were explored.

Initially, explosive bonding was applied [22]. The bonding takes place by an explosively driven, high-velocity angular impact of two metal surfaces at very high speeds creating huge contact pressure.

The bimetallic tubes have been produced in two steps: (i) explosive bonding of back extruded seamless $\mathrm{Nb}$ tube (approximately $4 \mathrm{~mm}$ wall thickness) with oxygen free $\mathrm{Cu}$ tube (wall thickness approximately $12 \mathrm{~mm}$ ) was carried out at High Energy Metals, USA; (ii) flow forming into $\mathrm{NbCu}$ tube of $4 \mathrm{~mm}$ wall thickness (approximately $1 \mathrm{~mm}$ $\mathrm{Nb}, 3 \mathrm{~mm} \mathrm{Cu}$ ) was done at the company Metall Specialrohr, Germany.

Another cladding technique for bimetallic $\mathrm{NbCu}$ tubes was developed at KEK in collaboration with the industry $[43,44]$ (hot bonding) and at DESY in collaboration with Fa. NuTech (Canada). The main idea is to protect the $\mathrm{Nb}$ from contamination at high temperatures by a $\mathrm{Cu}$ shield; a vacuum of $10^{-5}-10^{-6}$ mbar is created between $\mathrm{Nb}$ and $\mathrm{Cu}$ layers and is leak tight welded ("canning"). Either three concentric tubes $\mathrm{Cu} / \mathrm{Nb} / \mathrm{Cu}$ or three plates $\mathrm{Cu} / \mathrm{Nb} / \mathrm{Cu}$ can be sandwiched together by the process. Subsequently, a tube with smaller wall thickness can be produced from such material combination using hot extrusion or hot rolling with subsequent spinning or deep drawing procedures. High cladding quality is achieved with these processes. In combination with flow forming, the required tolerances in the wall thickness are produced.

\section{B. $\mathrm{NbCu}$ clad cavities}

Several single-cell $\mathrm{NbCu}$ clad cavities (as an example see Fig. 37) were fabricated at DESY. Both the necking and the expansion are carried out without intermediate constraint. The calibration at 500 bar was done afterwards. Some of the cells were additionally annealed at $560{ }^{\circ} \mathrm{C}$ for $2 \mathrm{hrs}$ before calibration in order to soften them.

The niobium end tubes with the NbTi flanges were connected to the $\mathrm{Nb}$ layer of the cavity by EB welding (Fig. 37). The welding of $0.7-1 \mathrm{~mm}$ thick $\mathrm{Nb}$ layer of the cavity with the $2 \mathrm{~mm}$ thick wall of the end tube does not cause any problem and provides sufficient stiffness for the single-cell cavity. $\mathrm{Cu}$ in the welding area needs to be removed carefully before welding to guarantee a leak tight weld joint. 


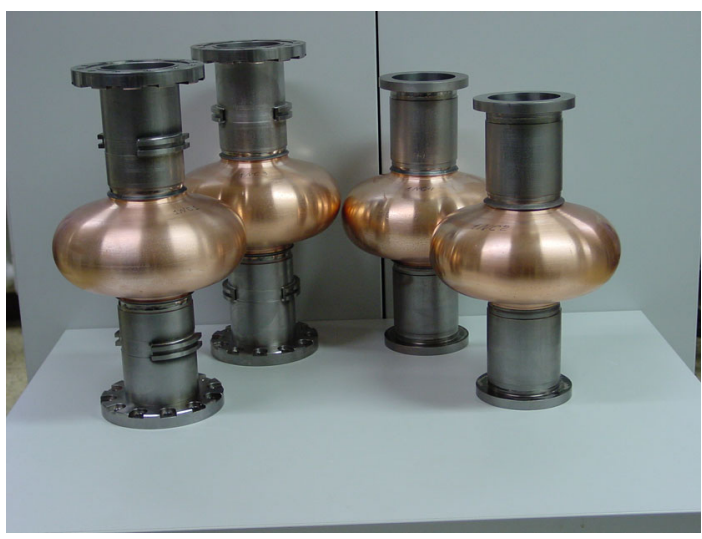

FIG. 37. $\mathrm{NbCu}$ clad cavities from explosive bonded tubes welded for preparation at DESY and JLab.

The stiffness of the connection can be additionally increased by covering this area with $\mathrm{Cu}$, for example by using a cold gas dynamic spray procedure developed by Kreye and his colleagues [46]. The minor degradation of $\mathrm{Nb}$ purity during spraying (from $\mathrm{RRR}=300$ to $\mathrm{RRR}=250$ ), and the matching microstructure and properties of sprayed $\mathrm{Cu}$ to bulk $\mathrm{Cu}$ (porosity ca. $1 \%$, small oxidation, electrical conductivity app. $80 \%$ of bulk $\mathrm{Cu}$ ) make this technique very practicable for applying to $\mathrm{NbCu}$ cavities.

The hydroforming technique was also explored for fabrication of multicell cavities from $\mathrm{Nb} / \mathrm{Cu}$ clad tubes. Several double-cell units were produced for KEK at DESY from sandwiched $\mathrm{Cu} / \mathrm{Nb} / \mathrm{Cu}$ tubes Rather small frequency deviation from cell to cells (within $1 \mathrm{MHz}$ ) indicated good reproducibility and high accuracy of the cell shape.

Some explosively bonded hydroformed $\mathrm{NbCu}$ clad cavities were treated and $\mathrm{rf}$ tested at DESY, KEK and Jefferson Lab. Consistently $E_{\text {acc }}$ values between 30 and $35 \mathrm{MV} / \mathrm{m}$ have been measured.

An excellent result achieved at Jefferson Lab with cavity $1 \mathrm{NC} 2$ even without EP is shown in Fig. 38. At the highest accelerating gradient, $E_{\mathrm{acc}}=40 \mathrm{MV} / \mathrm{m}$, the $Q_{\mathrm{o}}$ value was close to $10^{10}$.

The experimental data indicate that very good cavities can be fabricated from explosively bonded tubes. However, further experiences have shown that in some casesespecially for multicells - the $\mathrm{NbCu}$ bonding was locally not complete and these cavities quenched at low fields. It seemed that the poor bonding was insufficient to transfer the heat from the rf surface to the helium bath.

More stable behavior has been observed with the $\mathrm{NbCu}$ cavities produced from sandwiched hot roll bonded tube. The interactive diffusion between $\mathrm{Cu}$ and $\mathrm{Nb}$ provides for a more stable and complete bonding compared to the mechanical force in the explosion bonding method. For example the hydroformed single-cell cavity NSC-3 produced from hot roll bonded tube of company Nippon Steel

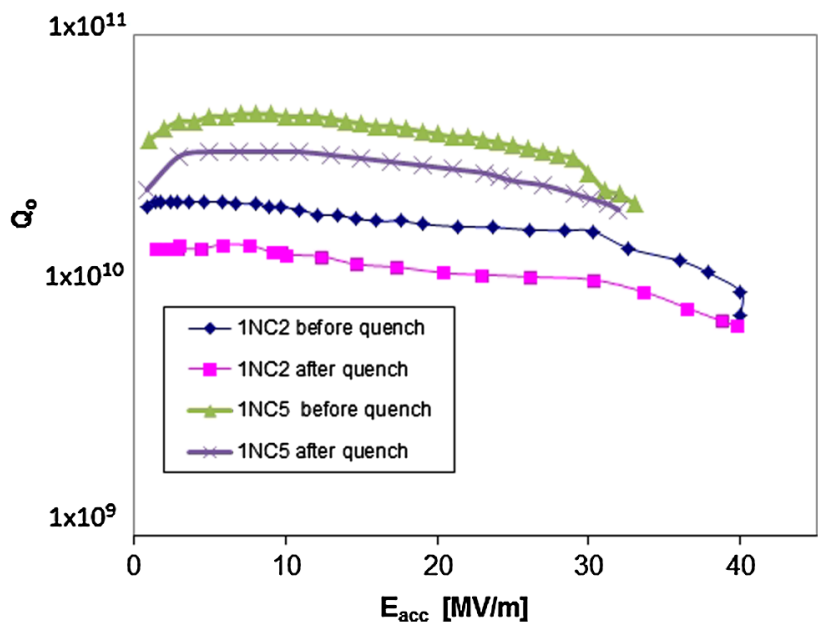

FIG. 38. Examples of rf results achieved in single-cell explosively bonded $\mathrm{NbCu}$ cavities. $1 \mathrm{NC} 2$ at $2 \mathrm{~K}$ : Preparation and $\mathrm{rf}$ tests done at JLab: $180 \mu \mathrm{m} \mathrm{BCP,} \mathrm{annealing} \mathrm{at} 800{ }^{\circ} \mathrm{C}$, baking at $140{ }^{\circ} \mathrm{C}$ for 30 hours, HPR. $1 \mathrm{NC} 5$ at $1.8 \mathrm{~K}$ : Preparation and rf tests done at KEK: CBP $50 \mu \mathrm{m}$, BCP $110 \mu \mathrm{m}$, HT $750^{\circ} \mathrm{C}$, EP $50 \mu \mathrm{m}$, baking at $130{ }^{\circ} \mathrm{C}$.

Co. (Japan), prepared and $\mathrm{rf}$ tested at KEK, shows an excellent $E_{\text {acc }}$ of approximately $39 \mathrm{MV} / \mathrm{m}$ (see Fig. 39).

\section{Drawbacks and perspectives of $\mathrm{NbCu}$ clad cavities}

Two disadvantages of the $\mathrm{NbCu}$ clad cavities prevent currently the practical application of $\mathrm{NbCu}$ cavities.

The first drawback is the large difference in recrystallization temperature of $\mathrm{Nb}$ and $\mathrm{Cu}$; this did not permit to reach optimal plastic properties in both $\mathrm{Cu}$ and $\mathrm{Nb}$ materials during annealing.

$\mathrm{Cu}$ can be fully recrystallized by annealing at $560^{\circ} \mathrm{C}$ for 2 hours with a grain size about $30 \mu \mathrm{m}$ and acceptable for hydroforming elongation before rupture (about 35\%-40\%). In contrast, niobium remains still hard after such annealing parameters with a deformed microstructure and without

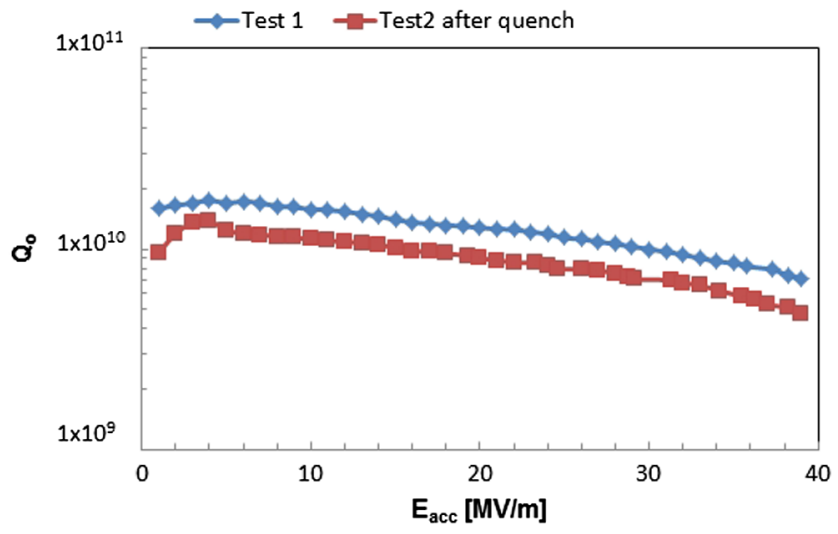

FIG. 39. $Q_{\mathrm{o}}\left(E_{\mathrm{acc}}\right)$ curve of the NSC-3 cavity at $2 \mathrm{~K}$ : CBP $50 \mu \mathrm{m}$, BCP $10 \mu \mathrm{m}$, annealing $750^{\circ} \mathrm{C} 3 \mathrm{~h}$, EP $70 \mu \mathrm{m}$ (K. Saito) [44]. 
pronounced grains. The well-known recrystallization temperature of $\mathrm{Nb}$ of approximately $800{ }^{\circ} \mathrm{C}$ is too high for $\mathrm{Cu}$ and annealing of $\mathrm{NbCu}$ bimetallic composition at this temperature will lead to significant grain growth in $\mathrm{Cu}$.

The high plastic properties of $\mathrm{Cu}$ play a leading role in the forming process of $\mathrm{NbCu}$ clad cavities. The less plastic $\mathrm{Nb}$ layer after tube annealing at $560^{\circ} \mathrm{C}$ follows the $\mathrm{Cu}$ during forming, because of the tight bonding. However, undesired effects cannot be avoided completely. The tendency to create cracks in the $\mathrm{Nb}$ layer at the iris area during necking is especially dangerous.

The situation can be improved by suitable alloying of the $\mathrm{Cu}$. It is well known that small additions of some metals (Hf, Ti, Cr, Zr, Mg, Sn, Mn, Al) increase the recrystallization temperature of $\mathrm{Cu}$. The $\mathrm{Cu}$ alloy $\mathrm{Cu} 0.15 \% \mathrm{Zr}$ commercially available [47] could be a good candidate for replacing the pure $\mathrm{Cu}$ in $\mathrm{NbCu}$ clad tubes.

This alloy has-after annealing at temperatures required for $\mathrm{Nb}$ recrystallization - the mechanical properties desired for hydroforming. As indicated in Fig. 40, a grain size of approximately $20-50 \mu \mathrm{m}$ can be reached after annealing at $800^{\circ} \mathrm{C}$. The measured elongation before local thinning is $>30 \%$.

Unfortunately, the alloying of $\mathrm{Cu}$ will increase the number of scattering centers for electrons and reduce the thermal conductivity. However, experiments have shown that the thermal conductivity of $\mathrm{Cu} 0.15 \% \mathrm{Zr}$ remains high enough (ca. $150 \mathrm{~W} / \mathrm{m} \mathrm{K}$ at $4.2 \mathrm{~K}$ ). This value is comparable with that of high purity $\mathrm{Nb}$. In addition, the thermal conductivity can be increased by special heat treatment [47].

A $\mathrm{Nb} \mathrm{Cu0.15 \% Zr} \mathrm{clad} \mathrm{tube} \mathrm{of} \mathrm{approximately} 1.8 \mathrm{~m}$ length has been produced for DESY at the company NuTech (Canada) by forward extrusion using the method described above. Single-cell cavities have been hydroformed at DESY from this tube without any appearance of cracks.

At the present time, two single-cell $\mathrm{NbCu}$ clad cavities are waiting for the preparation and for the rf tests.

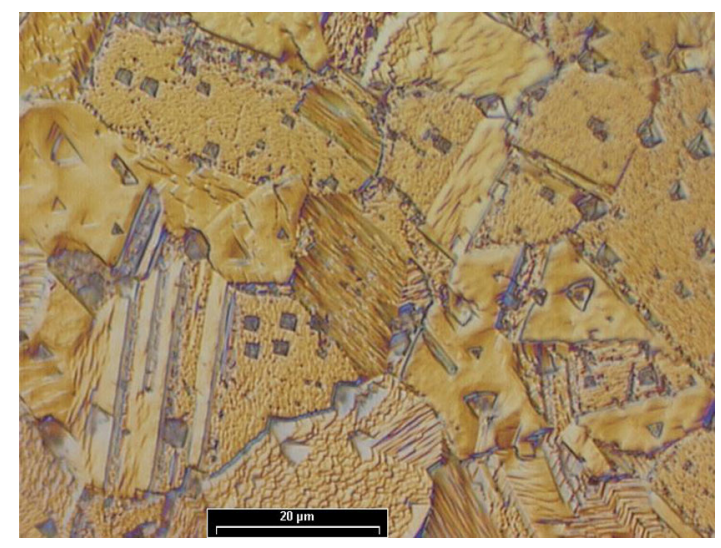

FIG. 40. Microstructure of $\mathrm{Cu} 0.15 \% \mathrm{Zr}$ after annealing at $800{ }^{\circ} \mathrm{C}$ for 2 hours.

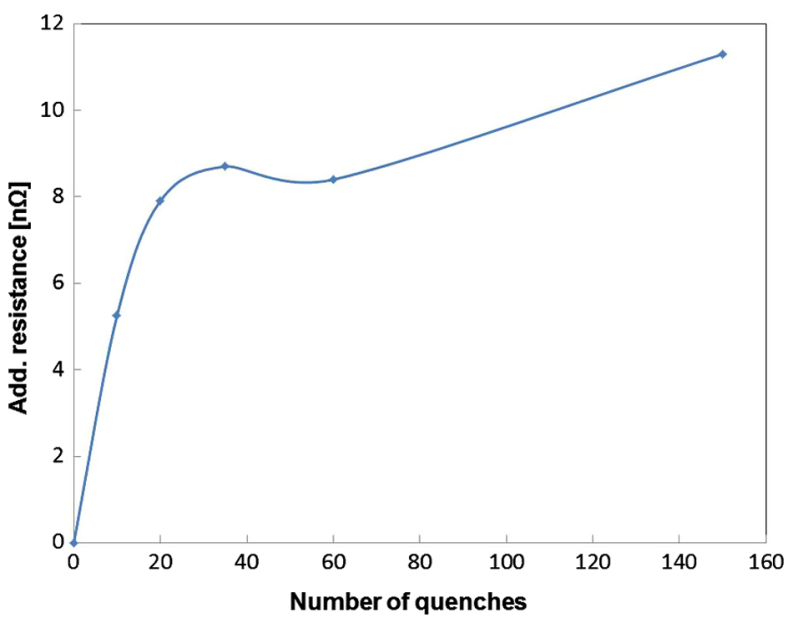

FIG. 41. Additional surface resistance after quenches in the cavity $1 \mathrm{NC} 2$ at ca $40 \mathrm{MV} / \mathrm{m}$.

The second undesirable drawback of bimetallic $\mathrm{NbCu}$ clad cavities is related to $Q_{\mathrm{o}}$ degradation caused by trapped external magnetic flux. In the bimetal composite thermocurrents can be developed due to temperature gradients appeared during fast cooldown, rf break downs, during multipacting or local heating like quench. Thermocurrents generate magnetic flux, which is trapped in the superconductor, when it transitions through the critical temperature (thermocoupling effect of bimetallic composition). These trapped fluxoids are normal conducting and add to the losses in a cavity, degrading the $Q$-value. The $Q_{\text {o }}$ degradation after quench in $\mathrm{NbCu}$ cavities can be seen in both Figs. 39 and 40. The increase in the surface resistance, mainly the residual resistance, was investigated in more detail on the best cavity 1NC2 (Fig. 41). As shown, the major increase in resistance happens roughly during the first 30 quenches.

A similar effect was observed in $\mathrm{Nb}_{3} \mathrm{Sn}$ cavities [48] and in sputtered $\mathrm{NbCu}$ cavities. Flux trapping in sputtered $\mathrm{NbCu}$ cavities is not yet fully explored, since the $Q_{\mathrm{o}}\left(E_{\mathrm{acc}}\right)$ performance is often limited by imperfections in the sputtered layers.

The degradation caused by trapped fluxoids can be reversed by warming up the cavity above $T_{\mathrm{c}}$ and recooling it slowly and avoiding temperature gradients along the cavity.

It has to be stressed that the trapping of magnetic flux due to the creation of thermocurrents in the bimetal, if large thermal gradients are present during cool down, is different from the cooling dynamic effect discussed for solid $\mathrm{Nb}$ cavities in [49]. Here fast cooling provides for efficient flux expulsion and therefore lower residual resistance.

\section{SUMMARY AND OUTLOOK}

The hydroforming technique was developed to the point enabling the fabrication of multicell cavities. Several 


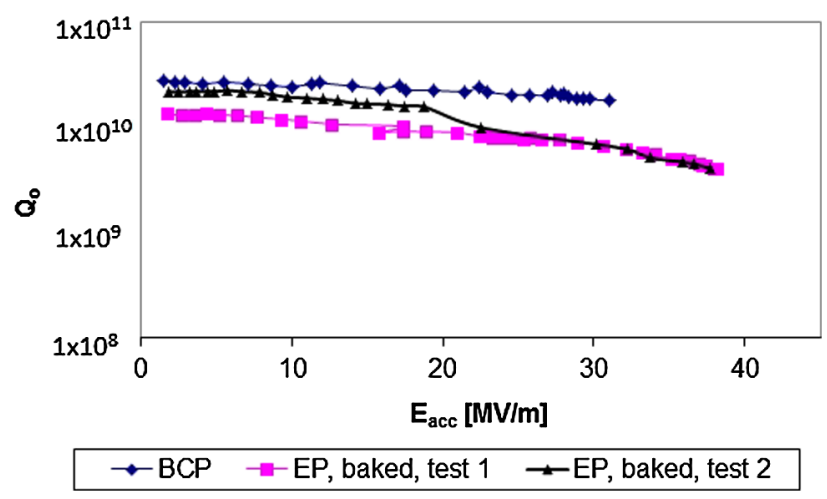

FIG. 42. Radio-frequency performance of TESLA shape single-cell cavity produced at company Butting by hydroforming. RRR250, radio-frequency tests done at JLab, EP done at KEK.

single-cell, two-cell, and three-cell bulk niobium cavities, produced by hydroforming at DESY, demonstrated accelerating gradient up to $40 \mathrm{MV} / \mathrm{m}$. The best hydroformed cavities performed as well as the best conventionally welded cavities.

The development work carried out at DESY has shown that the combination of hydroforming with tube cladding could be a very promising technology, since cavities hydroformed from $\mathrm{NbCu}$ bimetallic clad tubes reach excellent performances.

Three of the three-cell niobium units were combined to nine-cell cavities at Fa. E. Zanon. In total three nine-cell cavities have been fabricated, reaching accelerating gradients of $E_{\text {acc }}=27-35 \mathrm{MV} / \mathrm{m}$. One of these cavities was "dressed" with a helium tank and was integrated into the cryomodule for the FLASH accelerator, where it is operated reliably for a few years. Our whole experience is an indication that the hydroforming technique has successfully passed the proof of principle test.

The remaining task is the industrialization of the manufacturing process. Until now, industry is reluctant to invest in hydroforming equipment for series production, because a market for mass production of elliptical cavities is not visible. However, the industrialization of this technique is definitely a feasible task as proven by the company Butting (Germany). The company created simple equipment and fabricated a single-cell $\mathrm{Nb}$ cavity by a technique similar to the one developed at DESY. Cavity 1BT1 was produced without any intermediate constraints or intermediate annealing from deep drawn $3 \mathrm{~mm}$ thick Nb300 tube provided by DESY. The accelerating field of this cavity reached $E_{\text {acc }} \sim 39 \mathrm{MV} / \mathrm{m}$ after common EP treatment (see Fig. 42).

Furthermore, on the basis of its first experiences with hydroforming Butting conducted a study for industrial cavity production by hydroforming, including cost estimation [50]. It turned out that fabrication by hydroforming was approximately 10\%-15\% more expensive than the costs for conventionally welded cavities (compared to a study of the company NOELL [51]). However, in reality the conventional production for the European XFEL cavity was by far more expensive than the NOELL study predicted. One the other hand, the investing costs for the hydroforming machine estimated by Butting were too high. This means that the cost comparison between welded and hydroformed cavities definitely needs to be revisited.

The experiences with the welded cavities for the European XFEL are a case that can stress advantages for hydroforming. Burned holes, niobium splatter, incomplete weld penetration, rough surface of the EBW seam (especially at the overlap), etching pits in the HAZ (so-called "cat eyes"), deviation from straightness (eccentricity that required additional correction during tuning and reduction in shape accuracy): all these flaws will be absent in hydroformed cavities. In addition, precise machining is required for the critical welds at the equator or iris areas, demanding clean surface preparation (degreasing, etching, rinsing, drying in the clean room) and delicate assembly. Moreover, rather often quench limitations at $E_{\text {acc }} \sim$ 20-25 MV/m have been observed during the production [52], which are in most cases related to welding seam problems. Hydroforming avoids all of these problems.

The results of a statistical analysis of unloaded quality factor $\mathrm{Q}_{\mathrm{o}}$ (at $\left.5 \mathrm{MV} / \mathrm{m}\right)$, residual surface resistance $R_{\text {res }}$, medium field (5-20 MV/m) $Q_{\mathrm{o}}$ slope of different types of TESLA shape cavities (hydroformed, fine grain, Ingot, single crystal), of different treatment procedures (BCP, EP, Baking, HPR etc.), material from different $\mathrm{Nb}$ suppliers and cavity manufacturing companies were reported in Ref. [53] using rf data from the DESY database [54].

This analysis indicated, that (i) $Q_{0}$ at low fields and residual surface resistance values for hydroformed cavities are placed in the middle range compared to other types of cavities. (ii) The medium field $Q_{\mathrm{o}}$ slope value for hydroformed cavities tends to be a somewhat smaller and is located on the bottom of all data area. (iii) Assuming that the only difference between hydroformed and conventionally welded cavities are the welding seams, it can be concluded that the influence of the welding seam on the cavity behavior is not dramatic, if the before mentioned flaws can be avoided. (iv) However, the hydroforming procedure avoids all the flaws, possibly occurring during preparation for welding and during welding itself.

Hydroforming has the drawback that only the outside shape of a cell can be precisely formed. The accuracy of the inside shape ( $r$ surface, determining the frequency of the cell) and its reproducibility depends on wall thickness tolerances of the tubes and wall thickness changes during hydroforming. These two aspects can be eliminated easily during series production by stringent control of the uniformity of tube dimensions and hydroforming parameters during the ramp up phase. This will lead to uniformity of the cell shape and possibly minimize the need for tuning of multicell cavities. This seems to be one of the real advantages of hydroforming for serial production. 


\section{ACKNOWLEDGMENTS}

We would like to express the best gratitude to our colleagues of DESY and INR (Russia) who worked very engagedly all these years with us. The following significantly contributed to the development of hydroforming technology: H. Kaiser, I. Gonin, T. Khabibulline, V. Puntus, G. Weichert, G. Meyer, A. Sulimov, A. Ermakov and A. Scassirskaja. Success in development of the hydroforming technique would not be possible without the work of K. Saito (KEK) on cavity preparation at the state of the art level and rf tests of the hydroformed cavities. Many thanks to A. Matheisen, D. Proch, B. van der Horst, G. Kreps, H. Wen for support in our work at DESY. This work was done in collaboration with INR (Russia). Many thanks to L. Kravchuk for tireless pursue and support of the joint efforts.

[1] Hydroforming for Advanced Manufacturing, edited by M. Koc (Woodhead Publishing Limited, England, 2008), p. 396.

[2] F. Dohmann and P. Bieling, Grundlagen und anwendung des innenhochdruckumformens, Blech. Rohre. Profile. 38, 379 (1991).

[3] F. Dohmann and P. Bieling, Tool parameter and tool data in expanding internal high pressure forming, Umformtechnik 26, 23 (1992).

[4] H. Padamsee, J. Knobloch, and T. Hays, RF Superconductivity for Accelerators, 2nd ed. (Wiley-VCH, Weinheim, Germany, 2008), p. 521.

[5] H. Padamsee, RF Superconductivity (Wiley-VCH, Weinheim, Germany, 2009), p. 448.

[6] W. Singer, X. Singer, S. Aderhold, A. Ermakov, K. Twarowski, R. Crooks, M. Hoss, F. Scholz, and B. Spaniol, Surface investigation on prototype cavities for the European x-ray free electron laser, Phys. Rev. ST Accel. Beams 14, 050702 (2011).

[7] L. D. Cooley, D. Burk, C. Cooper, N. Dhanaraj, M. Foley, D. Ford, K. Gould, D. Hicks, R. Novitski, A. Romanenko, R. Schuessler, C. Thompson, and G. Wu, Impact of forming, welding, and electropolishing on pitting and the surface finish of SRF cavity niobium, Applied Superconductivity Conference, Washington, D.C. (2010), presentation 5MZ-01.

[8] P. Kneisel, G. Ciovati, J. Sekutowicz, A. Matheisen, X. Singer, and W. Singer, Development of a superconducting connection for niobium cavities, in Proceedings of the 22nd Particle Accelerator Conference, PAC-2007, Albuquerque, NM (IEEE, New York, 2007), WEPMS062.

[9] T. Fujino et al., Status of the seamless L-band cavity fabrication at KEK, in Proceedings of the 7th Workshop on RF Superconductivity SRF95, Paris, France, 1995, http:// www.jacow.org/index.php?n=Main.Proceedings.

[10] V. Palmieri, Progress on spun seamless cavities, in Proceedings of the 12th Workshop on RF Superconductivity SRF2005, Ithaca, New York, 2005, http://www.jacow.org/ index.php?n=Main.Proceedings.
[11] S. Dujardin et al., Hydroforming monolithic cavities in the $300 \mathrm{MHz}$ range, in Proceedings of the 2nd EPAC, Nice, 1990, http://www.jacow.org/index.php? $\mathrm{n}=$ Main.Proceedings.

[12] J. L. Kirchgessner, Forming and welding of niobium for superconducting cavities, in Proceedings of the Workshop on RF Superconductivity (CERN, Geneva, 1984), pp. 533-543.

[13] C. Z. Antoine et al., Hydroforming at Saclay: First issues, in The 8th Workshop on RF Superconductivity, Abano Terme, Padova, Italy, 1997, http://www.jacow.org/index .php?n=Main.Proceedings.

[14] C. Antoine, Materials and surface aspects in the development of SRF niobium cavities, EUCARD-CERN Monographs, (Institute of Electronic Systems Warsaw University of Technology, Warsaw, 2012), Vol. 12, p. 106.

[15] M. Yamanaka, Y. Ajima, H. Ionue, Y. Watanabe, T. Saeki, T. Kubo, and S. Yamaguchi, Cavity fabrication study in CFF at KEK, in Proceedings of the 16th International Workshop on RF Superconductivity (Paris, France, 2013), TUIOC06.

[16] C. Compton, D. Baars, T. Bieler, J. Bierwagen, S. Bricker, W. Hartung, D. Pendell, R. York, L. Cooley, H. Jiang, and B. Kephart, Studies of alternative techniques for niobium cavity fabrication, in Proceedings of the 15th International Workshop on RF Superconductivity SRF2007, Beijing, China, 2007, pp. 429-433, WEP01, http://accelconf.web .cern.ch/AccelConf/srf2007/HTML/AUTHOR.HTM.

[17] P. Mazot, Contribution a lètude des mecanismes de la deformation plastique du niobium at de ses alliages entre 20 ET $1.200^{\circ} \mathrm{C}$, Ph.D. thesis, Poitiers, France, 1970.

[18] C. Z. Antoine and D. Cochet, Hydroforming of niobium RF cavities: Mechanical properties of $\mathrm{Nb}$ in relation to its forming ability, in The 7th SRF International Workshop, Gif-sur-Yvette, France, 1995, pp. 581-585, SRF95F09, http://www.jacow.org/index.php?n=Main.Proceedings.

[19] I. Gonin, I. Jelezov, H. Kaiser, W. Singer, M. Oehring, H.-G. Priesmeyer, and R. Schnieber, Hydroforming test of back extruded niobium tube, in Proceedings of the 1997 Workshop on RF Superconductivity, Abano Terme, Padova, Italy, 1997, pp. 590-597, SRF97C19, http://www .jacow.org/index.php?n=Main.Proceedings.

[20] X. Singer, High purity niobium for TESLA test facility, Mater. Technol. 7-9, 28 (2003).

[21] I. Gonin, H. Kaiser, D. Proch, and W. Singer, Finite element simulation of the TESLA cavity hydroforming process, in Proceedings of the 1995 Workshop on RF Superconductivity, Gif-sur-Yvette, France, 1995, pp. 565-569, SRF95F07, http://www.jacow.org/index.php?n=Main .Proceedings.

[22] W. Singer, H. Kaiser, X. Singer, G. Weichert, I. Jelezov, T. Khabibuline, A. Skasyrskaia, P. Kneisel, T. Fujino, and K. Saito, Hydroforming of superconducting TESLA cavities, in Proceedings of the 10th Workshop on RF Superconductivity, Tsukuba, Japan, 2001, pp. 170-176, FA009, http://www.jacow.org/index.php?n=Main.Proceedings.

[23] W. Singer and I. Zhelezov, Verfahren zur herstellung von schweissnahtlosen hochfrequenzresonatoren, Patent No. 10 2007037 835, DESY 22607, Hamburg, Germany, 2007. 
[24] H. Kaiser, D. Proch, W. Singer, S. Esin, L. Kravchuk, I. Jelezov, V. Samohvalov, and A. Stepanov, Some technological methods for superconducting cavity manufacturing, Proceedings of the 5th European Particle Accelerator Conference, EPAC'96, Barcelona, Spain, 1996, p. 129, http://accelconf.web.cern.ch/AccelConf/ e96/contents.html.

[25] W. Singer, Seamless/bonded niobium cavities, Physica (Amsterdam) 441C, 89 (2006).

[26] I. Gonin, I. Jelezov, H. Kaiser, T. Khabibuline, W. Singer, and $\mathrm{X}$. Singer, Advances at DESY in hydroforming of TESLA cavities, in Proceedings of the International Workshop on Radiofrequency Superconductivity (Los Alamos National Laboratory, Santa Fe, NM, 1999), pp. 538-541, THA002.

[27] W. Singer, SC cavities; Material, fabrication and QA. Tutorial, in Proceedings of the 14th International Workshop on RF Superconductivity, SRF2009, Tutorials, 2009, Dresden, Germany, http://accelconf.web.cern.ch/ AccelConf/SRF2009/CONTENTS/tutorials_de.htm.

[28] K. Lange, Umformtechnik. Handbuch für Industrie und Wissenschaft (Springer-Verlag, Berlin, 1984), Band 1-4.

[29] I. Gonin, I. Jelezov, H. Kaiser, T. Khabiboulline, X. Singer, W. Singer, H.-G. Brokmeier, and R. Schnieber, Hydroforming of back extruded niobium tubes, in Proceedings of the International Workshop on Radiofrequency Superconductivity (Los Alamos National Laboratory, Santa Fe, NM, 1999), pp. 528-531, WEP042.

[30] W. Singer, SC cavities; Material, fabrication and QA. Tutorial, in Proceedings of the 13th International Workshop on RF Superconductivity, SRF2007, Beijing, China, Tutorials, 2007, Beijing, China, http://accelconf.web.cern .ch/AccelConf/srf2007/TUTORIAL/INDEX.HTML.

[31] Gmelins handbuch der anorganischen chemie: Niob, Teil A (Springer-Verlag, Berlin, 1974), p. 356.

[32] X. Singer, W. Singer, I. Jelezov, A. Matheisen, P. Kneisel, G. Ciovati, and M. Morrone, Hydroforming of multi-cell niobium and $\mathrm{NbCu}$-clad cavities, in Proceedings of the $23 \mathrm{rd}$ Particle Accelerator Conference, Vancouver, Canada, 2009 (IEEE, Piscataway, NJ, 2009), pp. 950-952, TU5PFP055.

[33] W. Singer, A. Ermakov, G. Kreps, A. Matheisen, X. Singer, K. Twarowski, R. Crooks, P. Kneisel, and I. N. Zhelezov, Nine-cell TESLA shape cavities produced from hydroformed cells, Proceedings of the 15th International Conference on RF Superconductivity, SRF2011, Chicago, Illinois, USA, 2011, p. 431, TUPO026, http://accelconf .web.cern.ch/AccelConf/SRF2011/html/author.htm.

[34] L. Lilje, High accelerating gradients in $1.3 \mathrm{GHz}$ niobium cavities, in Proceedings of the 10th Workshop on RF Superconductivity, SRF2001, Tsukuba, Japan, 2001, pp. 287-291, http://accelconf.web.cern.ch/AccelConf/ srf01/html/author.htm.

[35] W. Singer, I. Gonin, I. Jelezov, H. Kaiser, T. Khabibuline, P. Kneisel, K. Saito, and X. Singer. Hydroforming of TESLA cavities at DESY, in Proceedings of the European Particle Accelerator Conference, Vienna, 2000 (EPS, Geneva, 2000), pp. 327-329.

[36] P. Kneisel, How resilient are niobium rf cavities, Report No. JLab-TN-14-007, 2014.
[37] G. Issarovitch, D. Proch, X. Singer, D. Reschke, and W. Singer, Development of centrifugal barrel polishing for treatment of superconducting cavities, in Proceedings of the 11th Workshop on RF Superconductivity SRF2003, Luebeck, Germany, 2003, TuP56, http://accelconf.web .cern.ch/AccelConf/SRF2013/html/author.htm.

[38] P. Kneisel, W. Singer, and X. Singer, Summary of test results from seamless cavities manufactured at DESY, Report No. JLab - TN - 14- 012, 2014.

[39] W. Singer, I. Jelezov, X. Singer, A. Matheisen, P. Kneisel, G. Ciovati, and M. Morrone, Preliminary results from multi-cell seamless niobium cavities fabricated by hydroforming, in Proceedings of the XXIV Linear Accelerator Conference, Victoria, British Columbia, Canada, 2008, THP043, http://accelconf.web.cern.ch/AccelConf/ LINAC08/html/author.htm.

[40] P. Kneisel, G. Ciovati, X. Singer, W. Singer, and I. Jelezov, Performance of 3-cell seamless niobium cavities, in Proceedings of the 14th International Workshop on RF Superconductivity, SRF2009, Berlin, Germany, 2009, pp. 731-734, THPPO058, http://accelconf.web.cern.ch/ AccelConf/LINAC08/html/author.htm.

[41] J.-H. Thie, A. Goessel, J. Iversen et al., Mechanical design of automatic cavity tuning machines, in Proceedings of the 14th International Workshop on RF Superconductivity SRF2009, Berlin, Germany, 2009, pp. 797-800, THPPO074, http://accelconf.web.cern.ch/ AccelConf/SRF2009/html/author.htm.

[42] A. D. Palczewski, R. L. Geng, G. Eremeev, I. Jelezov, W. Singer, and X. Singer, Quench studies and preheating analysis of seamless hydroformed cavities processed at Jefferson Laboratories, in Proceedings of the 16th International Workshop on RF Superconductivity, Paris, France, 2013.

[43] K. Saito, T. Fujino, N. Hitomi, H. Inoue, Y. Yamazaki, V. Palmieri, W. Singer, P. Kneisel, K. Ohara, and S. Tsukada, $\mathrm{R} \& \mathrm{D}$ of $\mathrm{Nb} / \mathrm{Cu}$ clad seamless cavities at KEK, in Proceedings of the 10th Workshop on RF Superconductivity, 2001, Tsukuba, Japan, pp. 523-530.

[44] I. Itoh, K. Saito, H. Inoue, and W. Singer, Hot roll bonding method for $\mathrm{Nb} / \mathrm{Cu}$ clad seamless SC cavity, in Proceedings of the 11th Workshop on RF Superconductivity SRF2003, Luebeck, Germany, 2003, TuP40, http://accelconf.web.cern .ch/AccelConf/SRF2003/html/author.htm.

[45] V. Palmieri, Deposition techniques already applied in the past to superconducting resonator prototyping. Tutorial, in Proceedings of the 13th International Workshop on RF Superconductivity SRF2007, Beijing, China, 2007, http:// accelconf.web.cern.ch/AccelConf/srf2007/TUTORIAL/ INDEX.HTML.

[46] J. Hallier, Durch kaltgasspritzen erzeugte kupfer- und niobschichten und deren einsatzmöglichkeiten beim Bau des TESLA-linearbeschleunigers, Diploma thesis, University of Bundeswehr, 2002, p. 46.

[47] ASTM No. C 15000, zirconium copper.

[48] M. Peiniger, Experimentelle untersuchungen an supraleitenden $\mathrm{Nb}_{3} \mathrm{Sn}$-resonatoren im mikrowellenbereich, Ph.D. thesis, University Wuppertal, 1989, WUB-DIS 89-1, p. 96. 
[49] A. Romanenko, A. Grassellino, O. Melnychuk, and D. A. Sergatskov, Dependence of the residual surface resistance of superconducting radio frequency cavities on the cooling dynamics around Tc, J. Appl. Phys. 115, 184903 (2014).

[50] Industrial cavity fabrication. Study, BUTTING Edelstahlrohre, G. Holler, DESY-Project No. B4214-99, 1999.

[51] H. Kaiser and K.-H. Wahl, Industrial cavity fabrication study, NOELL (ASTRIUM), Project: TESLA-Studie, 2000.

[52] W. Singer, J. Iversen, A. Matheisen, H. Weise, and P. Michelato, The challenge and realization of the cavity production and treatment in industry for the European XFEL, in Proceedings of the 16th International Workshop on RF Superconductivity SRF2013, Paris, France, 2013, MOIOA03, http://accelconf.web.cern.ch/AccelConf/ SRF2013/html/author.htm.

[53] A. Ermakov, W. Singer, and X. Singer, Unloaded quality factor $Q_{\mathrm{o}}$ of prototype European XFEL cavities, large grain and hydroformed cavities, in Proceedings of the 16th International Workshop on RF Superconductivity, Paris, France, 2013.

[54] P. D. Gall, A. Gössel, and V. Gubarev, A database for superconducting cavities for the TESLA test facility, in Proceedings of the 11th Workshop on RF Superconductivity SRF2003, Luebeck, Germany, 2003, TUP12, http:// accelconf.web.cern.ch/AccelConf/SRF2003/html/author .htm. 